\title{
Pretreatment and Encapsulation of Ion Exchange Resins in Polyethylene
}

\author{
M. Ali, R.M. Doty, and P.D. Kalb
}

October 1994

\author{
Work Conducted by the \\ Environmental \& Waste Technology Center \\ Dept. of Advanced Technology \\ Brookhaven National Laboratory \\ Upton, NY 11973
}

Work Conducted Under a Cooperative Research and Development Agreement (CRADA) between

Vectra Technologies, Columbia, SC and United States Department of Energy

CRADA No. BNL-C-93-02

Contract No. DE-AC02-76CHOOO16

\section{MASTER}


THIS PAGE IS BLANK 


\begin{abstract}
Ion exchange resins were successfully encapsulated in low-density polyethylene (LDPE) using the single screw encapsulation process. The ion exchange resins were thermally pretreated in an oven to decrease swelling properties. The waste forms obtained, showed minor dimensional and weight changes during a 90-day water immersion test conducted. The thermal pretreatment of the resin and the mechanical properties of the LDPE were considered factors in keeping the final waste forms from complete structural failure due to swelling. The data obtained for the changes in volume and weight during the 90-day water immersion were used to make recommendations on maximum and conservative waste loadings. For thermally pretreated cation, anion, and mixed bed (2:1), the maximum waste loading (wt \%) for encapsulation in LDPE, using the extrusion process, is $70 \mathrm{wt} \%$. The conservative waste loadings, for which the changes in weight and volume were stable, are: $50 \mathrm{wt} \%$ for pretreated cation ion exchange resin and $60 \mathrm{wt} \%$ for pretreated anion and mixed bed ion exchange resin.
\end{abstract}




\section{THIS PAGE IS BLANK}




\section{TABLE OF CONTENTS}

Page

Abstract iii

List of Figures $\ldots \ldots \ldots \ldots \ldots \ldots \ldots \ldots \ldots \ldots \ldots \ldots \ldots \ldots \ldots \ldots \ldots$

List of Tables $\ldots \ldots \ldots \ldots \ldots \ldots \ldots \ldots \ldots \ldots \ldots \ldots \ldots \ldots \ldots \ldots \ldots \ldots$

1.0 Introduction $\ldots \ldots \ldots \ldots \ldots \ldots \ldots \ldots \ldots \ldots \ldots \ldots \ldots \ldots \ldots \ldots \ldots$

2.0 Properties of Ion Exchange Resin Beads $\ldots \ldots \ldots \ldots \ldots \ldots \ldots \ldots$

3.0 Properties of Low-Density Polyethylene $\ldots \ldots \ldots \ldots \ldots \ldots \ldots \ldots \ldots$

4.0 Pretreatment of Ion Exchange Resins $\ldots \ldots \ldots \ldots \ldots \ldots \ldots \ldots \ldots \ldots \ldots \ldots \ldots$

$4.1 \quad$ Pretreatment Methods $\ldots \ldots \ldots \ldots \ldots \ldots \ldots \ldots \ldots \ldots \ldots$

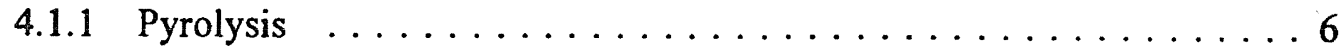

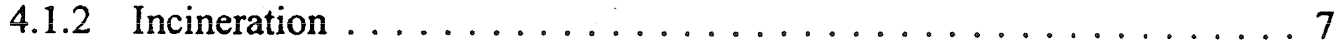

4.1 .3 Quick-freezing $\ldots \ldots \ldots \ldots \ldots \ldots \ldots \ldots \ldots \ldots \ldots \ldots \ldots \ldots$

5.0 Preparation of Simulated Ion Exchange Resin Waste $\ldots \ldots \ldots \ldots$

5.1 As-received Ion Exchange Resin $\ldots \ldots \ldots \ldots \ldots \ldots \ldots \ldots$

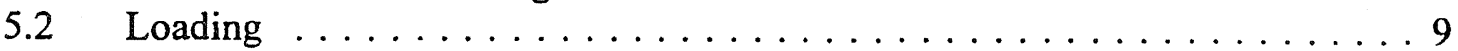

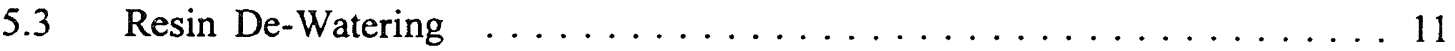

5.4 Pretreatment for Polyethylene Encapsulation Process $\ldots \ldots \ldots \ldots \ldots 12$

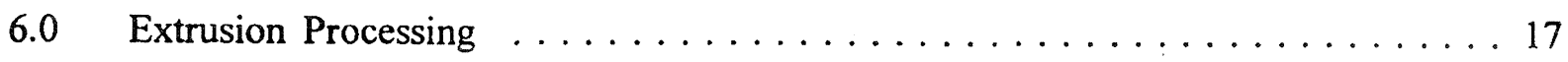

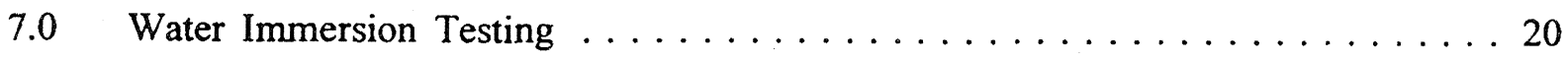

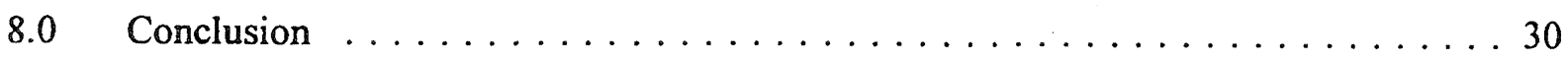

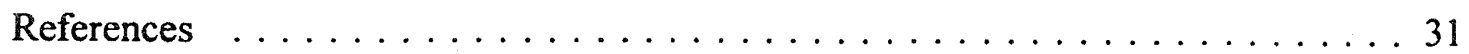

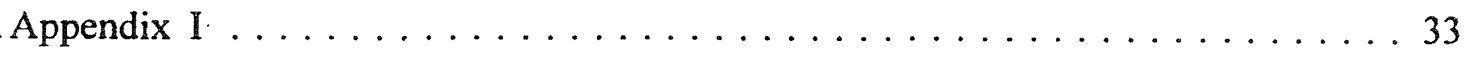

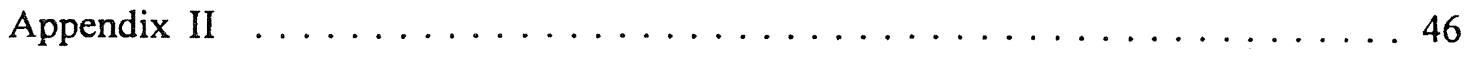




\section{LIST OF FIGURES}

Page

Figure 5.1 Cation resin bead (IRN-77), la, dried in oven @ $100^{\circ} \mathrm{C}$ for 18 hours $\ldots 13$

Figure 5.2 Cation resin bead (IRN-77), la, dried in oven @ $118^{\circ} \mathrm{C}$ for 18 hours

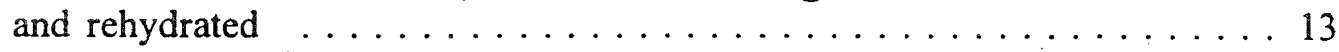

Figure 5.3 Cation resin bead (IRN-77), 6b, heated in oven @ $300^{\circ} \mathrm{C}$ for 1 hour $\ldots .13$

Figure 5.4 Cation resin bead (IRN-77), 6b, heated in oven @ 300 ${ }^{\circ} \mathrm{C}$ for 1 hour

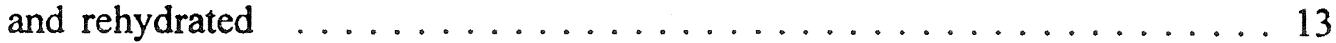

Figure 5.5 Anion resin bead (IRN-78), 6c, heated in oven @ $300^{\circ} \mathrm{C}$ for 1 hour ... 14

Figure 5.6 Anion resin bead (IRN-78), 6c, heated in oven @ $300^{\circ} \mathrm{C}$ for 1 hour

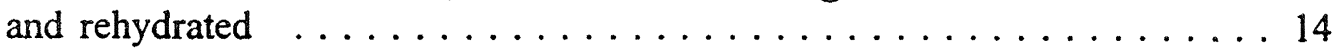

Figure 6.1 The single-screw extruder processing unit (Davis-Standard (Model \# DS15H) extruder and Merrick (Model \# 3000)

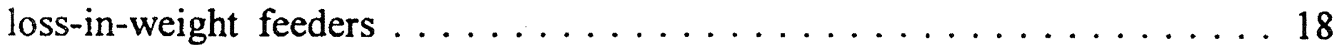

Figure 7.1 Sample contained in cup of deionized water for the 90-day

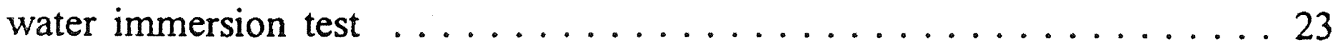

Figure 7.2 Average (Samples A and B) \% Change in Weight, vs. Time (Days) for Pretreated Cation (IRN-77) Ion Exchange Resin Immersed in Deionized Water . . . . . . . . . . . . . . . . . . 24

Figure 7.3 Average (Samples A and B) \% Change in Weight, vs. Time (Days) for Pretreated Anion (IRN-78) ion Exchange Resin Immersed in

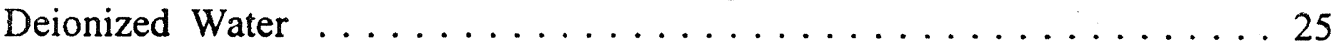

Figure 7.4 Average (Samples A and B) \% Change in Weight, vs. Time (Days) for Pretreated Mixed Bed (2:1 ratio) Ion Exchange Resin Immersed

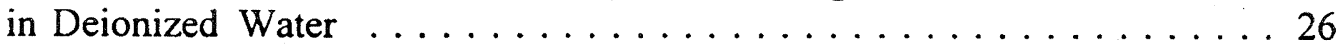

Figure 7.5 Average (Samples A and B) \% Change in Volume, vs. Time (Days) for Pretreated Cation (IRN-77) Ion Exchange Resin Immersed in Deionized Water

Figure 7.6 Average (Samples A and B) \% Change in Volume, vs. Time (Days) for Pretreated Anion (IRN-78) Ion Exchange Resin Immersed in Deionized Water ........................ 28 


\section{LIST OF FIGURES (Continued)}

Figure 7.7 Average (Samples A and B) \% Change in Volume, vs. Time (Days)

$\underline{\text { Page }}$ for Pretreated Mixed Bed (2:1 ratio) Ion Exchange Resin Immersed in Deionized Water

Figure A.1 Volume (cu.cm) of Sample A, measured using a caliper, vs. Time (Days) for Pretreated Cation (IRN-77) Ion Exchange Resin Immersed in Deionized Water ........................ . . 34

Figure A.2 Volume (cu.cm) of Sample B, measured using a Caliper, vs. Time (Days) for Pretreated Cation (IRN-77) Ion Exchange Resin Immersed in Deionized Water

Figure A.3 Weight (grams) of Sample A vs. Time (Days) for Pretreated Cation (IRN-77) Ion Exchange Resin Immersed in Deionized Water . . . . . . 36

Figure A.4 Weight (grams) of Sample B vs. Time (Days) for Pretreated Cation (IRN-77) Ion Exchange Resin Immersed in Deionized Water . . . . . . 37

Figure A.5 Volume (cu.cm) of Sample A, measured using a caliper, vs. Time (Days) for Pretreated Anion (IRN-78) Ion Exchange Resin Immersed in Deionized Water ....................... 38

Figure A.6 Volume (cu.cm) of Sample B, measured using a Caliper, vs. Time (Days) for Pretreated Anion (IRN-78) Ion Exchange Resin Immersed in Deionized Water ......................... 39

Figure A.7 Weight (grams) of Sample A vs. Time (Days) for Pretreated Anion (IRN-78) Ion Exchange Resin Immersed in Deionized Water . . . . . . 40

Figure A.8 Weight (grams) of Sample B vs. Time (Days) for Pretreated Anion (IRN-78) Ion Exchange Resin Immersed in Deionized Water

Figure A.9 Volume (cu.cm) of Sample A, measured using a Caliper, vs. Time (Days) for Pretreated Mixed Bed (2:1 ratio) Ion Exchange Resin Immersed in Deionized Water

Figure A.10 Volume (cu.cm) of Sample B, measured using Caliper, vs.. Time (Days) for Pretreated Mixed Bed (2:1 ratio) Ion Exchange Resin Immersed in Deionized Water . . . . . . . . . . . . . . . . 43

Figure A.11 Weight (grams) of Sample A vs. Time (Days) for Pretreated Mixed Bed (2:1 ratio) Ion Exchange Resin Immersed in Deionized Water . . . . 44

Figure A.12 Weight (grams) of Sample B vs. Time (Days) for Pretreated Mixed Bed (2:1 ratio) Ion Exchange Resin Immersed in Deionized Water 


\section{LIST OF TABLES}

Page

Table 5.1 Density (p), moisture content ( $w t \%)$, and $\mathrm{pH}$ for as-received, $100 \%$ loaded, and $60 \%$ loaded IRN-77, IRN-78, and Mixed Bed resin beads

Table 5.2 The number of grams of $\mathrm{NaCl}$ and milliliters (ml) of deionized water required for a saturated solution to load the resins $100 \%$ and $60 \% \ldots 10$

Table 5.3 Density (p), moisture content (wt \%), and pH for $100 \%$ and $60 \%$ loaded damp IRN-77, IRN-78, and Mixed Bed resin beads . . . . 10

Table 5.4a Changes in diameter for cation (IRN-77) ion exchange resin beads loaded to $60 \%$ with $\mathrm{Na}^{+}$and thermally degraded in the oven $\ldots \ldots \ldots 16$

Table 5.4b Changes in diameter for anion (IRN-78) ion exchange resin beads loaded to $60 \%$ with $\mathrm{Cl}^{-}$and thermally degraded in the oven $\ldots \ldots \ldots 16$

Table 6.1 Specifications of Davis-Standard (Model \# DS15H) Single Screw Extruder . . . . . . . . . . . . . . . . . . . . 19

Table 6.2 The zone temperatures, melt temperature, melt pressure, current draw, screw speed, and vacuum pressure monitored during processing . . . . 19

Table 7.1 Maximum and Conservative waste loadings obtained, using 90-day water immersion test, for thermally pretreated ion exchange in LDPE . . . . . 23

Table A.1 Volume Measurements Using a Caliper for Cation (IRN-77), Sample A, Ion Exchange $\operatorname{Resin} \ldots \ldots \ldots \ldots . \ldots . \ldots . . \ldots 47$

Table A.2 Volume Measurements Using a Caliper (IRN-77), Sample B, Ion Exchange Resin ....................... 48

Table A.3 Weight Measurements for Cation (IRN-77), Sample A, Ion Exchange Resin . . . . . . . . . . . . . . . . . . . . . . . 49

Table A.4 Weight Measurements for Cation (IRN-77), Sample B, Ion Exchange Resin . . . . . . . . . . . . . . . . . . . . . 49

Table A.5 Volume Measurements Using a Caliper for Anion (IRN-78), Sample A, Ion Exchange Resin ..................... 50

Table A.6 Volume Measurements Using a Caliper for Anion (IRN-78), Sample B, Ion Exchange Resin ..................... 51 


\section{LIST OF TABLES (Continued)}

Page

Table A.7 Weight Measurements for Anion (IRN-78), Sample A, Ion Exchange $\operatorname{Resin} \ldots \ldots \ldots \ldots \ldots \ldots . \ldots \ldots$

Table A.8 Weight Measurements for Anion (IRN-78), Sample B, Ion Exchange Resin . . . . . . . . . . . . . . . . . . . . 52

Table A.9 Volume Measurements Using a Caliper for Mixed Bed (2:1 ratio), Sample A, Ion Exchange Resin .................. 53

Table A.10 Volume Measurements Using a Caliper for Mixed Bed (2:1 ratio), Sample B, Ion Exchange Resin . . . . . . . . . . . . . . . . 54

Table A.11 Weight Measurements for Mixed Bed (2:1 ratio), Sample A, Ion Exchange Resin . . . . . . . . . . . . . . . . 55

Table A.12 Weight Measurements for Mixed Bed (2:1 ratio), Sample B, Ion Exchange Resin . . . . . . . . . . . . . . . . . 55 


\subsection{INTRODUCTION}

Ion exchange resin columns, with either individual cation or anion resins or a homogeneous mixture of both resin types (mixed bed), are used in nuclear plants to treat radioactive streams. These streams include primary coolant, turbine condensate, water in the spent fuel storage pools, and liquid radwaste resulting from different plant operations. In the treatment of these radioactive streams, the ion exchange resins interchange ions from its solid phase with radioactive ionic species and particulate matter. As a result the resins concentrate radioactive species. The activities for ion exchange resin can typically be 0.1-10 microcurie/cc for resin used in waste processing and may exceed 500 microcurie/cc in primary coolant purification [1].

Spent ion exchange resins can be regenerated by introducing a flow of solution which will displace the exchanged ions and replace them with fresh counter ions. However, ion exchange resin columns have to be replaced in nuclear facilities if either of the following criteria is satisfied [2]: (1) depletion of exchange capacity (breakthrough) or (2) significant personnel dose as a consequence of the contained radioactivity. At nuclear facilities, the possible dose hazards to workers from the handling and exposure to the high activity spent ion exchange resin, rather than the exhaustion of ion exchange service life as a chemical exchanger, is usually the reason for replacement of ion exchange columns [2].

The disposal of spent ion exchange resin requires that the migration of radionuclides be minimized. Encapsulation, using cement, bitumen, and polyethylene, has been previously shown [3] to restrict the physical washing from burial sites and reduce the surface area for contact by ground water and therefore reduce the potential for exchange of radionuclides on the resin with naturally occurring minerals in the ground water. Waste forms of ion exchange resin beads encapsulated in cement and bitumen, however, were characterized by excessive swelling and cracking due to expansion, from absorption of water, of the ion exchange resin beads.

Therefore, in this project loaded ion exchange resin were first thermally pretreated, to reduce the hygroscopic properties of the ion exchange beads, and then encapsulated in lowdensity polyethylene, using an extruder. A 90-day water immersion test was conducted to determine the swelling of the waste form and, also, to determine if any catastrophic failure of the waste form will occur. 


\subsection{PROPERTIES OF ION EXCHANCE RESIN BEADS}

The most used ion exchange resin beads in the nuclear industry are the synthetic organic resin beads. The gel structure (matrix) of these resin beads is composed of an irregular, macromolecular, 3-dimensional network of hydrocarbon chains (linear polystyrene chains crosslinked with divinylbenzene) [4]. The matrix carries ionic groups, such as $\mathrm{SO}_{3}{ }^{-}$(anion resin) and $\mathrm{NH}_{3}^{+}$(cation resin), which provide the exchange capability.

The non-uniform mesh width (heteroporosity) is determined by the degree of crosslinking. The random network is flexible and expands, or "swells", by taking up solvents. The swelling ability of the resin bead is determined by the mesh width and thus the degree of crosslinking. Highly cross-linked resin beads have a reduced ability to swell since the networks are rigid [4].

Gregor's Model $[5,6,7]$ is a practical way of looking at the swelling phenomena of the resin beads. In Gregor's Model, ion exchange resin are modeled as strong electrolytes with a matrix analogous to coiled springs. These coiled springs are under pressure when water absorption, by osmosis, swells the matrix. This swelling is finite and reaches an equilibrium when the tension of the coiled spring balances the osmotic pressure. At the equilibrium state the difference in the osmotic pressure $(\Pi)$ and the spring force $(\Sigma)$ is termed the swelling pressure

$$
P=\Pi-\Sigma
$$

The encapsulated resin beads will exert this swelling pressure on the encapsulating material.

The osmotic pressure, $\Pi$, can be defined as [7]

$$
\Pi=\nu R T \phi m
$$

where $v$ is the number of ions into which the electrolyte dissociates, $R(\mathrm{~J} / \mathrm{mol} \mathrm{K})$ the gas constant, $T(K)$ the absolute temperature, $\phi$ the osmotic coefficient, and $\mathrm{m}\left(\mathrm{mol} / \mathrm{m}^{2}\right)$, the molarity. The spring force $(\Sigma)$ can be obtained by [7]

$$
\Sigma=\alpha^{n} K
$$


where $\alpha$ is the water content, $\mathrm{n}$ is an empirical constant, and $\mathrm{K}(\mathrm{Pa})$ is the elastic constant of the bead. Using (2) and (3), (1) becomes

$$
P=\nu R T \phi m-\alpha^{n} K
$$

The experimental results of Matsuda et. al. [7] confirmed that Gregor's model, and thus (4), is valid for determining the swelling pressure, P. Matsuda et. al. [7] measured the swelling pressure to change over a range of 0-60 MPa for cation exchange resin with different properties and this agreed closely with the values calculated from (4). 


\subsection{PROPERTIES OF LOW DENSITY POLYETHYLENE}

Polyethylene is an organic polymer material of crystalline-amorphous structure, formed through the polymerization of ethylene gas at high and low pressure processes [8]. Several types of polymers (low density, linear low-density, and high density), each with its own characteristics, are formed. Low density polyethylene (LDPE), made by polymerizing ethylene gas at high pressure, was selected because of its relative ease of processibility due to lower processing pressures and temperatures and better material flow. These characteristics of polyethylene will enhance homogeneity and stability of the final waste form.

Pertinent physical and mechanical properties of LDPE are given in Table 3.1. LDPE is characterized with superior mechanical properties, such as compressive and tensile strength, which can allow for high waste loadings. LDPE is resistant to most acids, bases, and organics, as normally found in waste streams. LDPE has excellent resistance to water or moisture which is helpful in decreasing the absorption of water by the encapsulated ion exchange resin beads. LDPE waste forms will retain their physical and mechanical properties under normal temperature conditions but exhibit a loss in mechanical properties at temperatures above their glass transition temperature $\left(\mathrm{T}_{\mathrm{g}}\right)$.

Portland cement and bitumen are other materials which have been used to immobilize spent ion exchange resin beads. In comparison with polyethylene, Portland cement has excellent compressive strength but has very weak tensile strength. Portland cement is not wellsuited for immobilization of ion exchange resin beads because the hygroscopic properties of the resin beads can affect the hydration process in cement and thus make the final waste form unstable. In addition, expansion of resin beads in the presence of moisture exceeds cement's tensile strength, leading to severe waste form cracking. Ion exchange resin waste loading in cement is limited to $\leq 13 \mathrm{wt} \%$ to eliminate cracking [2]. 
Table 3.1: Physical and Mechanical Properties of Low Density Polyethylene (LDPE).

\begin{tabular}{|c|c|}
\hline Tensile Strength (psi) & $600-2300$ \\
\hline Elongation (\%) & $90-800$ \\
\hline Compressive Strength (lb/in $\left.{ }^{2}\right)$ & No Break \\
\hline Impact Strength & $0.20-0.36$ \\
\hline Hardness, Rockwell & M124-128 \\
\hline Specific Gravity & $0.917-0.932$ \\
\hline Water Absorption, 24hr & $<0.01$ \\
\hline
\end{tabular}




\subsection{PRETREATMENT OF ION EXCHANGE RESINS}

Pretreatment of spent ion exchange resin beads is done to reduce the waste volume to be encapsulated and to decrease the swelling properties of the beads. The reduction in waste volume is accomplished, using relatively simple processes, that eliminates interstitial liquids (i.e., water) or decreases the interstitial spaces. The effect of heat has been shown to decrease the hygroscopic properties of the ion exchange resin beads, as well [4]. Therefore, thermal pretreatment processes are used to decrease the swelling properties of the beads in the presence of moisture and thus make the final encapsulated waste package more stable.

\subsection{Pretreatment Methods}

Drying, compaction, vibration, and application of high confining pressure are examples of pretreatment methods which decrease the volume of the spent ion exchange resin [3]. Drying at $70^{\circ} \mathrm{C}$ has been shown to reduce the volume by $56 \%$ [3]. Volume reduction by compaction or vibration is relatively less effective (volume reduction of $7.8 \%$ for compaction and $7.1 \%$ for vibration) because of the uniform particle size, elastic properties, and particle cohesion properties of the resin beads [3]. Application of high pressure (e.g., $258 \mathrm{MPa}$ for one minute) has been demonstrated to decrease the volume by $40 \%$ [3].

The simple processes to decrease the volume of spent resin beads have no effect on swelling properties. However, ion exchange resin will loose some of their ability to swell if exposed to high temperatures. The exposure to high temperature alters the molecular composition of the ion exchange resin bead by decomposing the functional groups into gaseous forms. Therefore, thermal processes, such as pyrolysis and incineration, not only reduce volume but also significantly reduce the swelling properties of the ion exchange resin beads.

\subsubsection{Pyrolysis}

Pyrolysis, destruction of complex molecules by the use of heat in an inert environment, has been shown to decrease the hygroscopic properties of ion exchange resin beads [7]. The ion exchange resin matrix is decomposed at temperatures between $300-500{ }^{\circ} \mathrm{C}$. The volume of the ion exchange resin residue after pyrolysis is about nine times less than the original contaminated waste [3].

The effects of pyrolysis are different for cation and anion resin beads, even though the base 
polymer, styrene-divinylbenzene, is the same. The results of Matsuda et. al. [7] experiments on pyrolysis of ion exchange resin show that anion resin decompose in two stages, between $200-400{ }^{\circ} \mathrm{C}$, and the decomposition ratio was $90 \mathrm{wt} \%$ for above $400{ }^{\circ} \mathrm{C}$. The cation decomposed in one stage, between $200-300{ }^{\circ} \mathrm{C}$, and the decomposition ratio was $50 \mathrm{wt} \%$ even at $600{ }^{\circ} \mathrm{C}$. The hygroscopic properties $\left(\mathrm{g} \mathrm{H}_{2} \mathrm{O} / \mathrm{g}\right.$ residue) of cation reduced from 0.7 at 200 ${ }^{\circ} \mathrm{C}$ to 0.05 at $300{ }^{\circ} \mathrm{C}$. Matsuda et. al. attributed the differences between the cation and anion resins pyrolysis to the different functional groups, sulfonic acid and quaternary ammonium, respectively. Through experiments, Matsuda et. al. [9], discovered that the low decomposition of the cation during pyrolysis occurs due to the conversion of the sulfonic acids to sulfonyl and sulfur bridges between the base polymer. The formation of these bridges make the base polymer thermally stable and cause the weight loss of cation beads to be relatively less than anion beads during pyrolysis.

\subsubsection{Incineration}

Incineration can also be used to reduce the volume and decompose low level ion exchange resin beads. The two types of incinerators developed for commercial use are the fluidized-bed incinerator and an air-suspension burning device [10]. With incineration, an average volume reduction factor of $40 \%$ can be achieved [11]. The resins are difficult to combust, since tars and char form, therefore other materials, such as wood and coal, are added. The resins are incinerated, at temperatures around $1000^{\circ} \mathrm{C}$, in slurry form and the residual ash, a charcoal-like material, is immobilized.

Incineration of ion exchange resin can lead to excessively high radiation dose rates due to the concentration of activity in the ash product [12]. Complicated off-gas systems which incorporate treatment, filtration, sampling, and discharge equipment for the combustion

products are required. These factors make the siting and permitting of an incinerator facility difficult and significantly increase processing cost.

\subsubsection{Quick-freezing}

Freezing also changes the structure of the ion exchange resins beads [13]. Yim et. al. quick-froze ion exchange resin beads, which contained 40-60 wt\% moisture, using liquid nitrogen and solid carbon dioxide, and discovered that the freezing expansion pressure, estimated to be $100 \mathrm{MPa}$, destroys the structure of the bead. The resin beads did not recover 
their original structure after thawing.

Yim et. al. [13] tested the quick-freezing pretreatment for grinding of resin beads. They discovered that the grindability of cation resin beads increase by the quick-freeze pretreatment. Anion resins, which have a lower cross-linking than cation, can be ground easily without pretreatment. Therefore, the effects of quick-freezing, on anion resin beads, were not as significant as for cation resin beads. The particle size distribution for both types of resin, after grinding, was more uniform. 


\subsection{PREPARATION OF SIMULATED ION EXCHANGE RESIN WASTE}

\subsection{As-received Ion Exchange Resin}

Nuclear grade Amberlite ion exchange resins (Rohm and Haas Co.), typical of those used in the nuclear industry, were used. These are "gel" type synthetic ion exchange resins with elastic structures formed by crosslinking linear polystyrene with $8 \%$ divinylbenzene by weight. The cation form, IRN-77, is a strongly acidic resin and has sulfonic acid functionality. A minimum of $95 \%$ of its exchange sites are in the hydrogen form. Anion resin, IRN-78, is a strongly basic quaternary ammonium functionality resin, containing a minimum $80 \%$ of its exchange sites in the hydroxide form with a maximum of $5 \%$ in chloride form and a maximum of $15 \%$ in the carbonate form. Mixed bed resin was formed by combining two parts cation ion exchange resin and one part anion ion exchange resin by dry weight.

The density, water content, and the $\mathrm{pH}$ of the as-received resins were determined and are shown in Table 5.1. The density was calculated by measuring the weight using a standard laboratory scale and volume using a pycnometer. The water content of the resins was calculated according to ASTM Standard Test Method D2187-77, "Physical and Chemical Properties of Ion Exchange Resins," [14]. In this procedure, the mass loss of resins, due to drying in a gravity convection oven at $110^{\circ} \mathrm{C}$ for $18 \pm 2$ hours, is used to calculate the water moisture in the following manner:

$$
w t \% \text { water }=\frac{w t . \text { of wet resin }-w t . \text { of dry resin }}{w t . \text { of wet resin }} \times 100
$$

The $\mathrm{pH}$ was measured using a standard laboratory $\mathrm{pH}$ meter.

\subsection{Loading}

"Cold" (non-radioactive) cation and anion resins were batch loaded, to $60 \%$ and $100 \%$ of their sorption capacity (the number of ionogenic groups contained in the specific amount of resin material), in a solution of sodium chloride $(\mathrm{NaCl})$ and deionized water to provide $\mathrm{Na}^{+}$ and $\mathrm{Cl}^{-}$ions. The $60 \%$ loading is used to represent the activity level at which the ion exchange 
Table 5.1 : Density $(\rho)$, moisture content (wt \%), and $\mathrm{pH}$ for as-received, $100 \%$ loaded, and $60 \%$ loaded IRN-77, IRN-78, and Mixed Bed resin beads.

\begin{tabular}{|c|c|c|c|c|c|c|c|c|c|}
\hline & \multicolumn{3}{|c|}{ As-received } & \multicolumn{3}{|c|}{$100 \%$ Loaded } & \multicolumn{3}{|c|}{$60 \%$ Loaded } \\
\hline & $\begin{array}{c}\rho^{(a)} \\
\left(\mathrm{g} / \mathrm{cm}^{3}\right)\end{array}$ & $\begin{array}{l}\mathbf{w t} \\
\% \%^{(a)}\end{array}$ & $\mathbf{p H}$ & $\begin{array}{c}\rho^{(2)} \\
\left(\mathrm{g} / \mathrm{cm}^{3}\right)\end{array}$ & $w t \%\left({ }^{(4)}\right.$ & $\mathbf{p H}$ & $\begin{array}{c}\rho^{(\mathrm{n})} \\
\left(\mathrm{g} / \mathrm{cm}^{3}\right)\end{array}$ & $\begin{array}{l}\text { wt } \\
\%{ }^{(a)}\end{array}$ & pH \\
\hline $\begin{array}{l}\text { IRN } \\
-77\end{array}$ & 0.72 & 46.9 & 4.0 & 0.76 & 64.7 & 5.65 & 0.76 & 66.7 & 3.7 \\
\hline $\begin{array}{l}\text { IRN } \\
-78\end{array}$ & 0.82 & 35.2 & 10.2 & 0.86 & 65.9 & 10.3 & 0.81 & 72.4 & 12.4 \\
\hline $\begin{array}{l}\text { Mix. } \\
\text { Bed }\end{array}$ & 0.77 & 56.1 & 6.25 & 0.78 & 62.7 & 4.1 & 0.75 & 63.7 & N/A \\
\hline
\end{tabular}

(a) Average of 3 replicates

Table 5.2 : The number of grams of $\mathrm{NaCl}$ and milliliters (ml) of deionized water required for a saturated solution to load the resins $100 \%$ and $60 \%$.

\begin{tabular}{|c|c|c|c|c||}
\hline \multirow{2}{*}{} & \multicolumn{2}{|c|}{$100 \%$ Loading } & \multicolumn{2}{c|}{$60 \%$ Loading } \\
\cline { 2 - 5 } & g of $\mathrm{NaCl}$ & $\mathrm{ml} \mathrm{of} \mathrm{H}_{\mathbf{2}} \mathrm{O}$ & $\mathrm{g}$ of $\mathrm{NaCl}$ & ml of $\mathrm{H}_{2} \mathrm{O}$ \\
\hline IRN-77 & 766 & 2175 & 153.21 & 430 \\
\hline IRN-78 & 214.4 & $700^{(\mathrm{a})}$ & 85.91 & $341^{\text {(a) }}$ \\
\hline
\end{tabular}

(a) $100 \mathrm{ml}$ extra added for $\mathrm{Na}$ solubility 
resins are typically replaced in nuclear power plants. The sorption capacity of the dry cation and anion resins were obtained from the manufacturer to be $4.7 \mathrm{meq} / \mathrm{g}$ and $3.5 \mathrm{meq} / \mathrm{g}$, respectively. The number of grams $(\mathrm{g})$ of $\mathrm{NaCl}$ required for $100 \%$ and $60 \%$ loading were determined based on the equivalent quantity of dry resin (see Table 5.2).

The saturated solutions of $\mathrm{NaCl}$ were prepared using $100 \mathrm{ml}$ of deionized water for every 35.7 grams of $\mathrm{NaCl}$ (see Table 5.2). The resins were soaked in the saturated $\mathrm{NaCl}$ and deionized water solution for 18 hours, at $23{ }^{\circ} \mathrm{C}$, with occasional stirring. The resins were then drained, using a polyethylene sieve, and rinsed five times with deionized water.

\subsection{Resin De-Watering}

Resin de-watering was accomplished by a pressurized column technique to obtain a product similar to commercial de-watering processes. Salt loading solutions and rinse water were drained from the loaded IRN-77, IRN-78, and mixed bed resin slurry by using a column (3 3/8" ID x 18") through which argon (Ar) gas was forced through the top. The liquid from the resin slurry flowed through a glass fiber filter at the bottom of the column. The remaining liquid, held between the interstitial spaces of the resin beads by capillary forces, was removed by forcing Ar gas, at $2 \mathrm{psi}$, for $10 \mathrm{~min}$. (or until no moisture was observed). The resin prepared in this manner is termed "damp resin".

The density and moisture content of the $100 \%$ and $60 \%$ loaded damp IRN-77, IRN-78, and mixed bed resin beads were measured. The methods of measurement were the same as for the as-received resin. The results are tabulated in Table 5.3.

Table 5.3 : Density $(\rho)$, moisture content (wt \%), and pH for $100 \%$ loaded and $60 \%$ loaded damp IRN-77, IRN-78, and Mixed Bed resin beads.

\begin{tabular}{|c|c|c|c|c|c|c||}
\hline & \multicolumn{3}{|c|}{$100 \%$ Loaded } & \multicolumn{3}{c|}{$60 \%$ Loaded } \\
\cline { 2 - 7 } & $\begin{array}{c}\rho^{(\mathrm{a})} \\
\left(\mathrm{g} / \mathrm{cm}^{3}\right)\end{array}$ & wt \% & $\mathrm{pH}$ & $\begin{array}{c}\rho^{(\mathrm{a})} \\
\left(\mathrm{g} / \mathrm{cm}^{3}\right)\end{array}$ & wt \% & $\mathrm{pH}$ \\
\hline IRN-77 & 0.69 & 48.3 & 4.0 & 0.69 & 51.7 & 3.7 \\
\hline IRN-78 & 0.81 & 48.6 & 9.95 & 0.81 & 61.2 & 12.4 \\
\hline $\begin{array}{c}\text { Mixed } \\
\text { Bed }\end{array}$ & 0.74 & 49.7 & 8.2 & 0.73 & 53.4 & N/A \\
\hline
\end{tabular}

(a) Average of 3 replicates 


\subsection{Pretreatment for Polyethylene Encapsulation Process}

Previous development work conducted at Brookhaven National Laboratory (BNL) indicated that significantly higher ion exchange resin waste loadings could be achieved by polyethylene encapsulation than compared with conventional hydraulic cement processes (30 $w t \%$ vs. 13 wt $\%$, respectively), without suffering degradation under water immersion testing. For this project, ion exchange resins were pretreated in an attempt to further improve waste loading potential for polyethylene encapsulated ion exchange resins.

A thermal pretreatment method using a conventional convection oven was used. The purpose of this pretreatment method, similar to other pretreatment methods described in Section 4 , was to reduce waste volume and swelling properties of the ion exchange resin beads. The volume of the damp resin beads was reduced by evaporation of the remaining interstitial water. As in pyrolysis, the resin beads were thermally degraded by the decomposition of the functional groups into gaseous forms, effectively reducing the resin bead swelling and rendering the final encapsulated waste form more stable. This section describes the method for determining pretreatment parameters. Temperatures and residence time in the oven were varied to determine the point at which all the interstitial water will evaporate and the swelling properties of the individual beads will decrease. The beads were then removed from the oven and diameters of the individual beads were measured from magnified (magnification 200x) pictures, see Figures 5.1-5.6, of the thermally degraded ion exchange resin beads. The thermally degraded beads were rehydrated with de-ionized water and measurements of the diameters were taken again to determine the effect of the temperature and time on the hygroscopic nature of the beads. Results of various time and temperatures are described below and are shown in Table 5.4a and 5.4b:

Temperature: $110^{\circ} \mathrm{C}$ and Time: 18 hours

Both the dried anion and cation resin beads swelled when hydrated with deionized water. The swelling occurred even though the cation resin bead was craeked in various places.

Temperature: $200{ }^{\circ} \mathrm{C}$ and Time: 2 hours

The result of this increase in temperature and decrease in time had no effect on the swelling of the cation but the swelling of the anion decreased significantly. 
Figure 5.1: Cation resin bead (IRN-77), 1a, dried in oven@110 ${ }^{\circ} \mathrm{C}$ for 18 hour .

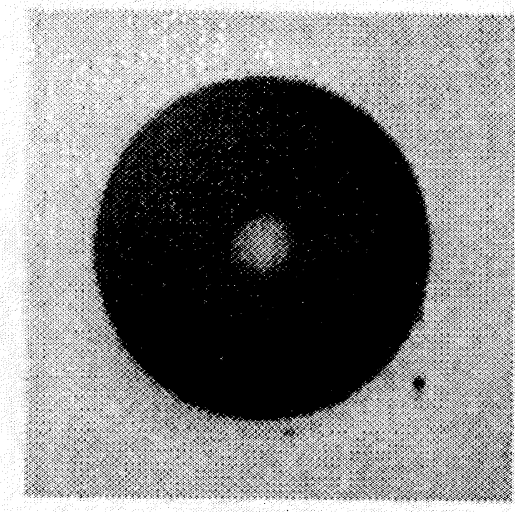

Figure 5.3: Cation resin bead (IRN-77), 6b, heated in oven@300 ${ }^{\circ} \mathrm{C}$ for 1 hour.

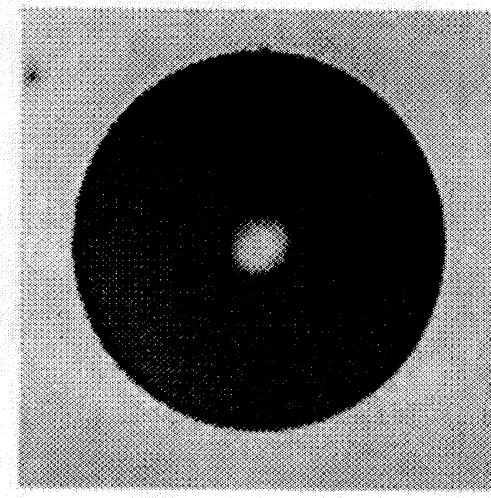

Figure 5.2: Cation resin bead (IRN-77), la, dried in oven@118 ${ }^{\circ} \mathrm{C}$ for 18 hours and rehydrated.

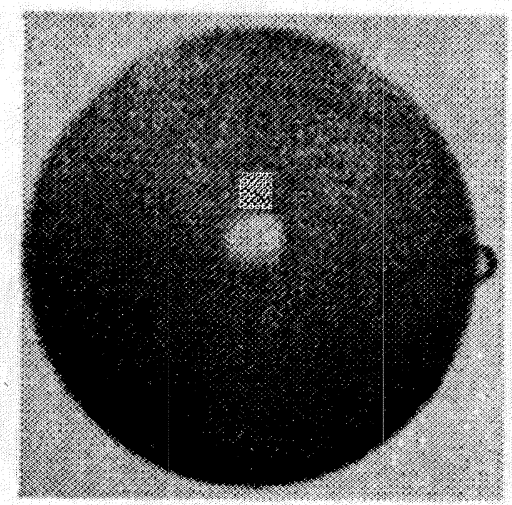

Figure 5.4: Cation resin bead (IRN-77), 6b, heated in oven@300 ${ }^{\circ} \mathrm{C}$ for 1 hour and rehydrated.

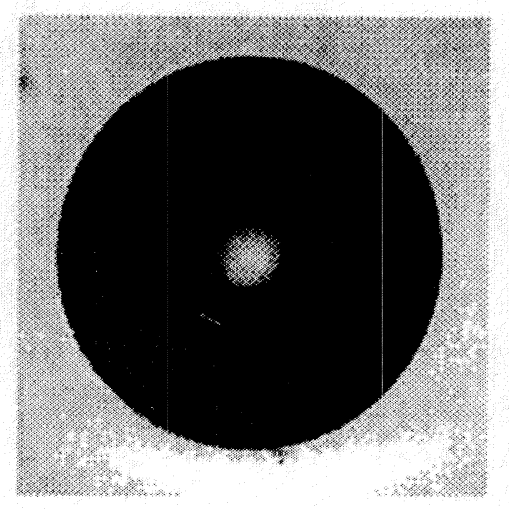


Figure 5.5: Anion resin bead (IRN-78), $6 c$, heated in oven@300다. for 1 hour.

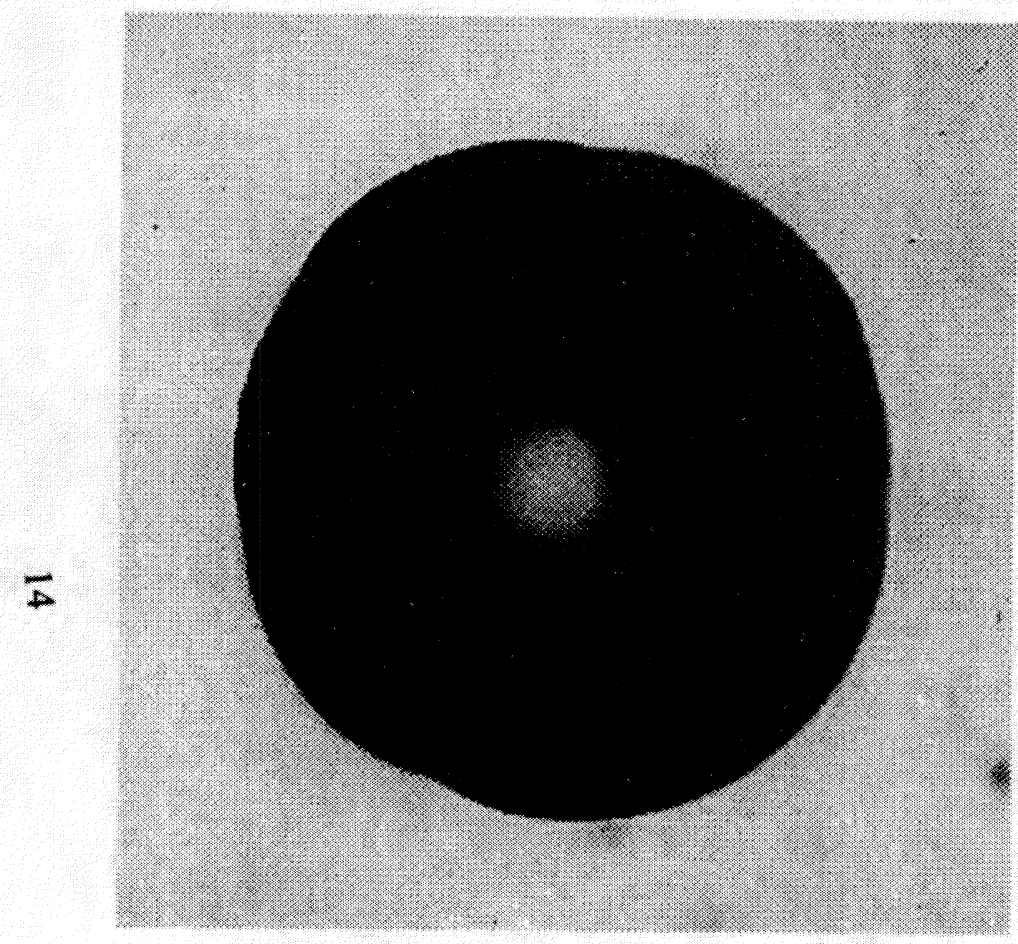

Figure 5.6: Anion resin bead (IRN-78), 6c, heated in oven@300 ${ }^{\circ} \mathrm{C}$ for 1 hour and rehydrated.

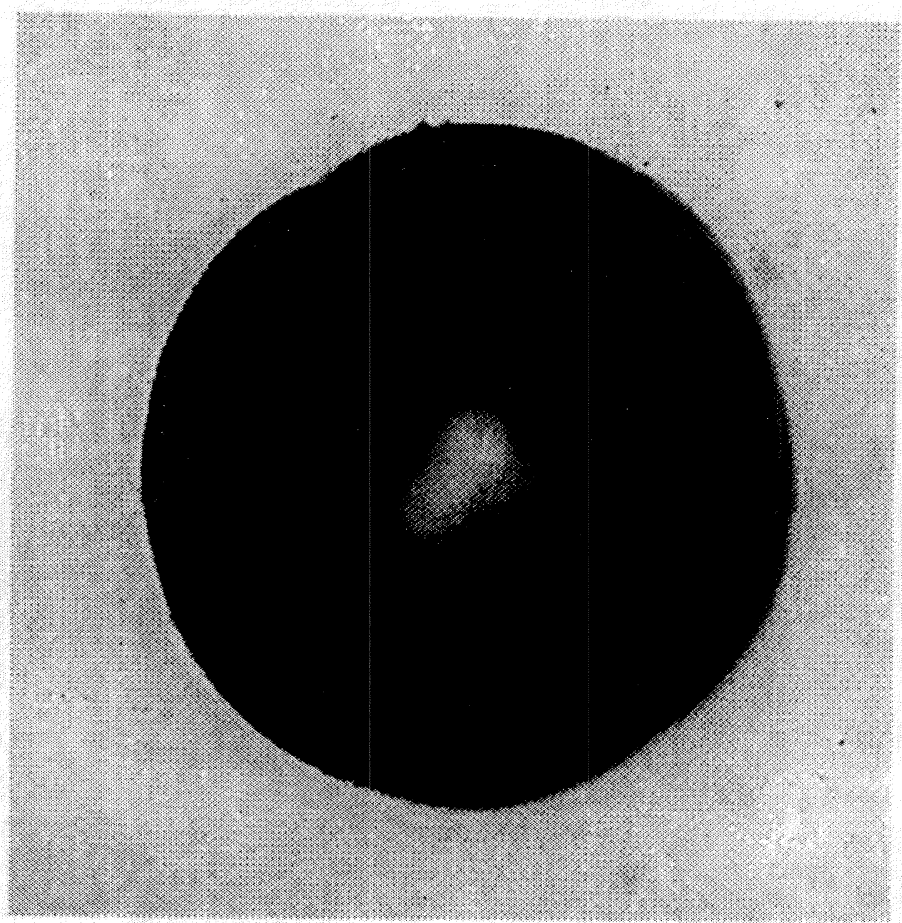


Temperature: $250{ }^{\circ} \mathrm{C}$ and Time: 1 hour

The increase in temperature caused the anion to loose its swelling capacity completely but the cation swelling capacity was not affected.

Temperature: $250^{\circ} \mathrm{C}$ and Time: 18 hours

The increase in time did not decrease the swelling capacity of the cation but instead caused part of the cation resin bead to break off due to an increase in internal pressure from hydration. The anion was observed to have lost its capacity to hydrate at this temperature and time.

Temperature: $400{ }^{\circ} \mathrm{C}$ and Time: 0.5 hours

The high temperature was chosen to determine if the resin beads will be catastrophicly destroyed and result in a decrease in swelling properties. After 0.5 hours the resin beads were found to be deformed and charred black. The swelling properties of the cation decreased significantly and the swelling properties of the anion resin bead disappeared.

Temperature: $300{ }^{\circ} \mathrm{C}$ and Time: 1 hour

The temperature was decreased to avoid breaking apart of the beads, and thus increasing the exposed surface area. The temperature was decreased to avoid the catastrophic break up of the resin beads. At $300 \mathrm{OC}$ both resin beads showed an excellent decrease in the swelling properties. Therefore this was the temperature and time at which the both resin beads were placed in the oven to be pretreated for the encapsulation process.

The temperature chosen for pretreatment is within the temperature range, $300-500{ }^{\circ} \mathrm{C}$, recommended by Matsuda et. al. [7] for pretreatment by pyrolysis. Also, the difference in swelling properties of anion and cation resins may possibly be due to their different functional groups, as was observed by Matsuda et. al. [9]. 
Table 5.4a: Changes in diameter for cation (IRN-77) ion exchange resin beads loaded to $60 \%$ with $\mathrm{Na}^{+}$and thermally degraded in the oven.

\begin{tabular}{|c|c|c|c|c|c|c|}
\hline Bead \# & $\begin{array}{c}\text { Temp. } \\
\left({ }^{\circ} \mathrm{C}\right)\end{array}$ & $\begin{array}{c}\text { Time } \\
\text { (Hours) }\end{array}$ & $\begin{array}{c}\text { Diam. } \\
\text { Hydra. } \\
\text { Bead } \\
(\mathbf{m m}) \\
\end{array}$ & $\begin{array}{l}\text { Diam. } \\
\text { Dried } \\
\text { Bead } \\
(\mathbf{m m})\end{array}$ & $\begin{array}{c}\text { Diff. in } \\
\text { Diam. } \\
\text { (mm) }\end{array}$ & $\begin{array}{c}\% \text { Inc. } \\
\text { in } \\
\text { Diam. }\end{array}$ \\
\hline 1 & 110 & 18 & .321 & .238 & .084 & 35.3 \\
\hline 2 & 200 & 2 & .338 & .250 & .088 & 35 \\
\hline 3 & 250 & 1 & .318 & .243 & .075 & 31 \\
\hline 4 & 250 & 18 & .338 & .238 & .100 & 42.2 \\
\hline $5 a$ & 400 & 0.5 & .293 & .269 & .024 & 8.9 \\
\hline $5 b$ & 400 & 0.5 & .258 & .230 & .028 & 12.1 \\
\hline $6 a$ & 300 & 1 & .229 & .222 & .006 & 2.8 \\
\hline $6 b$ & 300 & 1 & .218 & .211 & .008 & 3.6 \\
\hline $6 c$ & 300 & 1 & .230 & .222 & .008 & 3.4 \\
\hline
\end{tabular}

Table 5.4b: Changes in diameter for anion (IRN-78) ion exchange resin beads loaded to $60 \%$ with $\mathrm{Cl}^{-}$and thermally degraded in the oven.

\begin{tabular}{|c|c|c|c|c|c|c|}
\hline & Temp. & $\begin{array}{c}\text { Time } \\
\text { Bead \# }\end{array}$ & $\begin{array}{c}\text { Diam. } \\
\text { Hydra. } \\
\text { Bead } \\
(\mathbf{m m})\end{array}$ & $\begin{array}{c}\text { Diam. } \\
\text { Dried } \\
\text { Bead } \\
(\mathbf{m m})\end{array}$ & $\begin{array}{c}\text { Diff. } \\
\text { in } \\
\text { Diam. } \\
(\mathbf{m m})\end{array}$ & $\begin{array}{c}\text { \% Inc. } \\
\text { in } \\
\text { Diam. }\end{array}$ \\
\hline \hline $1 \mathrm{a}$ & 110 & 18 & .254 & .222 & .032 & 14.3 \\
\hline $1 \mathrm{~b}$ & 110 & 18 & .286 & .254 & .032 & 12.5 \\
\hline 2 & 200 & 2 & .262 & .258 & .004 & 1.48 \\
\hline 3 & 250 & 1 & .211 & .211 & 0 & 0 \\
\hline 4 & 250 & 18 & .211 & .211 & 0 & 0 \\
\hline 5 & 400 & 0.5 & .163 & .163 & 0 & 0 \\
\hline $6 \mathrm{a}$ & 300 & 1 & .204 & .204 & 0 & 0 \\
\hline $6 \mathrm{~b}$ & 300 & 1 & .216 & .211 & .005 & 2.4 \\
\hline $6 \mathrm{c}$ & 300 & 1 & .197 & .197 & 0 & 0 \\
\hline
\end{tabular}




\subsection{EXTRUSION PROCESSING}

The pretreated ion exchange resin beads were encapsulated in low-density polyethylene (LDPE) using the extrusion process. The solidification of the pretreated ion exchange resin beads in LDPE occurs, by heating, mixing, and extrusion, in one operation. The single-screw extruder used, Davis-Standard Model \# DS15H, consisted of the following main components (see Figure 1 and Table 6.1 for specifications): 1) Loss-in-weight feeders, 2) A single rotating auger-like screw, 3) A heated cylinder in which the screw rotates, and 4) An output die assembly to shape the final product.

The pretreated ion exchange resin beads and LDPE pellets are fed separately into the extruder by two Merrick, Model \# 3000, loss-in-weight feeders. The feeders are controlled by microprocessors that monitor the instantaneous weight loss as material is delivered. The actual mass feed rate is compared with the pre-set rate and adjustments in delivery speed are made automatically to keep the feed rate within about $1 \%$ of the set rate. The two individual controllers are regulated, in turn, by a master controller which monitors and adjusts the delivery of each feeder so that the resin bead/LDPE pellet ratio is maintained. The setting for the feeders were varied to maintain recipes of $10-70 \mathrm{wt} \%$ pretreated ion exchange resin beads and 90-30 wt\% LDPE.

The mixture of pretreated ion exchange resin beads and LDPE is conveyed through a heated cylinder by the motion of the rotating auger-like screw. The mixture is melted due to the frictional heat generated by the screw and by 5 electric resistance band heaters placed on the cylinder. External cooling fans are used to remove excessive heat from the cylinder. The screw rotation also assists in the mixing of the materials to a homogeneous state. A vent stack and vacuum system is used to vent the cylinder of any moisture or volatiles present in the

mixture. Zone temperatures, melt temperature, melt pressure, current draw, screw speed, and vacuum pressure were monitored during processing (See Table 6.2).

The molten mixture of ion exchange resin beads and LDPE is forced through an output die into a copper mold. The samples, $2.54 \mathrm{~cm}$ diameter $\times 2.54 \mathrm{~cm}$ height, are removed from the molds when they are cooled and solidified. 
Figure 6.1: The single-screw extruder processing unit (Davis-Standard (Model \# DS15H) extruder and Merrick (Model \# 3000) loss-in-weight feeders.

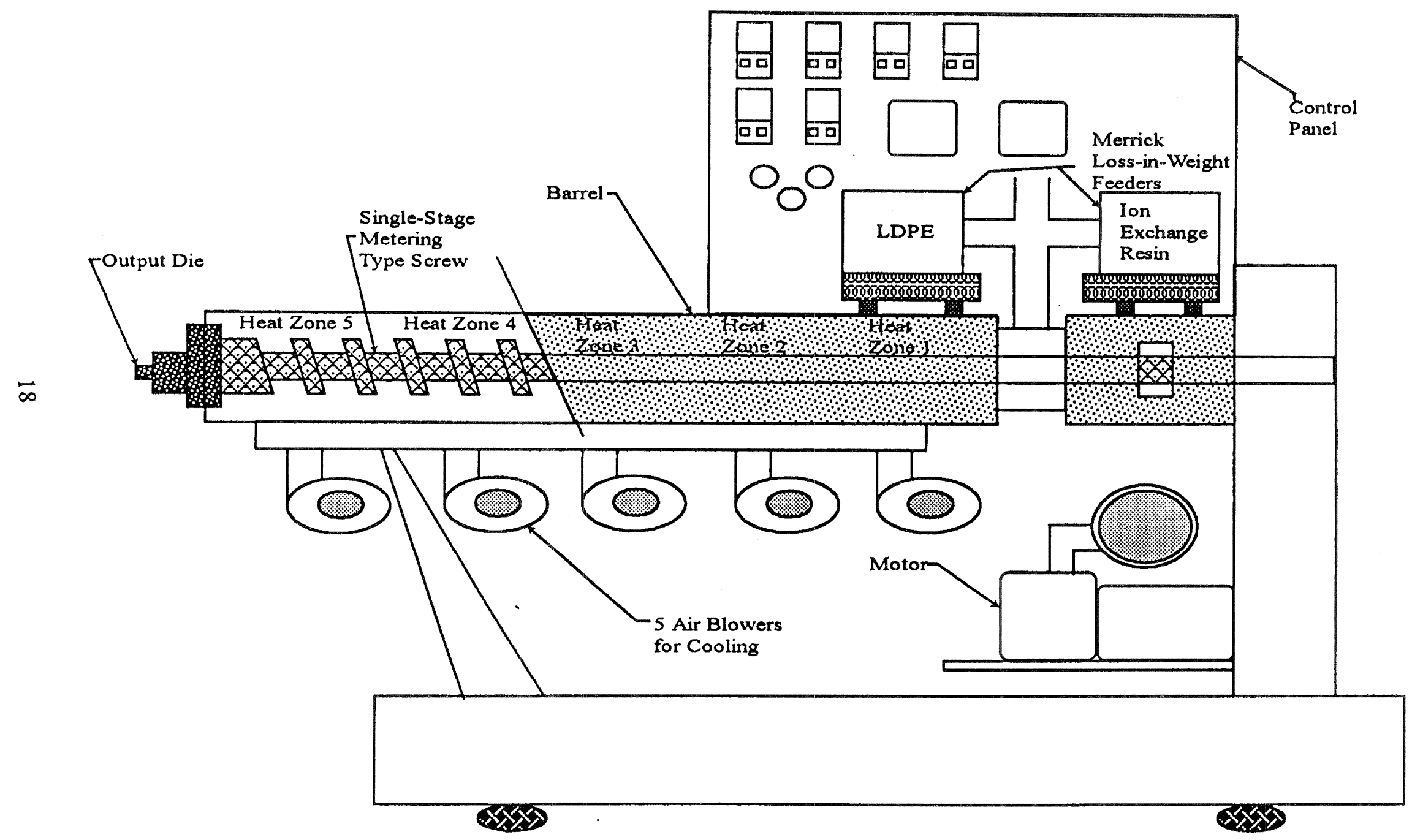


Table 6.1: Specifications of Davis-Standard (Model \# DS15H) Single Screw Extruder

\begin{tabular}{|c|c|}
\hline Diameter of Screw & $1-1 / 2 "$ \\
\hline L/D & $30: 1$ \\
\hline Barrel & Alloy Steel \\
\hline Barrel Cooling Zones & 5 Air-cooled \\
\hline Vent Stack and Vacuum System & Yes \\
\hline Gearbox & $24 \mathrm{HP} @ 125 \mathrm{rpm}$ \\
\hline Motor $(\mathbf{D C})$ & $10 \mathrm{HP}, 1750 \mathrm{rpm}$ \\
\hline
\end{tabular}

Table 6.2: The zone temperatures, melt temperature, melt pressure, current draw, screw speed, and vacuum pressure monitored during processing

\begin{tabular}{|c|c|}
\hline Zone 1 Temp. $\left({ }^{\circ} \mathbf{F}\right)$ & 240 \\
\hline Zone 2 Temp. $\left(^{\circ} \mathbf{F}\right)$ & 240 \\
\hline Zone 3 Temp. $\left({ }^{\circ} \mathbf{F}\right)$ & 280 \\
\hline Zone 4 Temp. $\left(^{\circ} \mathbf{F}\right)$ & 280 \\
\hline Zone 5 Temp. $\left({ }^{\circ} \mathbf{F}\right)$ & 300 \\
\hline Melt Temp. $\left(^{\circ} \mathbf{F}\right)$ & 300 \\
\hline Current Draw (amps) & 3.5 \\
\hline Screw Speed (rpm) & 20.0 \\
\hline Vacuum Pressure (in. of Hg) & 17 \\
\hline
\end{tabular}




\subsection{WATER IMMERSION TESTING}

\subsection{Procedure}

The samples of ion exchange resin encapsulated in LDPE were immersed in deionized water for 90 days. The volume of deionized water was chosen to be 10 times the surface area of the samples, as recommended by the Nuclear Regulatory Commission in the Branch Technical Position on Waste Form [15]. The samples and deionized water were contained in cups which were clearly marked with the type of sample. The samples were suspended by nylon string and completely immersed in water to prevent the samples from hitting the bottom or touching the sides (see Figure 7.1). The volume of the samples was calculated from measurements of the diameter and height, made with a digital caliper.

\subsection{Results}

The LDPE encapsulated anion (IRN-77), cation (IRN-78), and mixed bed (2 cation:1anion ratio) ion exchange resin waste forms maintained their integrity for the 90-day water immersion test. At waste loadings up to $70 \mathrm{wt} \%$, the waste forms remained free-standing monolithic solids, with no gross failure in structural integrity, and no surface cracks were observed. These waste loadings, are far superior than those reported using hydraulic cement, (13 wt\%) or LDPE (50 wt\%), in which no thermal pretreatment of the ion exchange resin was conducted. [2,8] However, dimensional and weight changes did occur, due to the water absorption by the waste forms, during the 90-day water immersion testing. For some waste forms, volume increases were still being recorded at the end of the 90-day water immersion test. Other waste forms showed less overall volume increases and appeared to reach an equilibrium in relation to weight and volume changes. These changes in volume and weight were used to determine conservative formulation recommendations (ion exchange resin-toLDPE ratio) for which catastrophic failure of the integrity of the waste form, under saturated conditions, is less likely. 
Figure 7.1: Sample contained in cup of deionized water for the 90-day water immersion test.

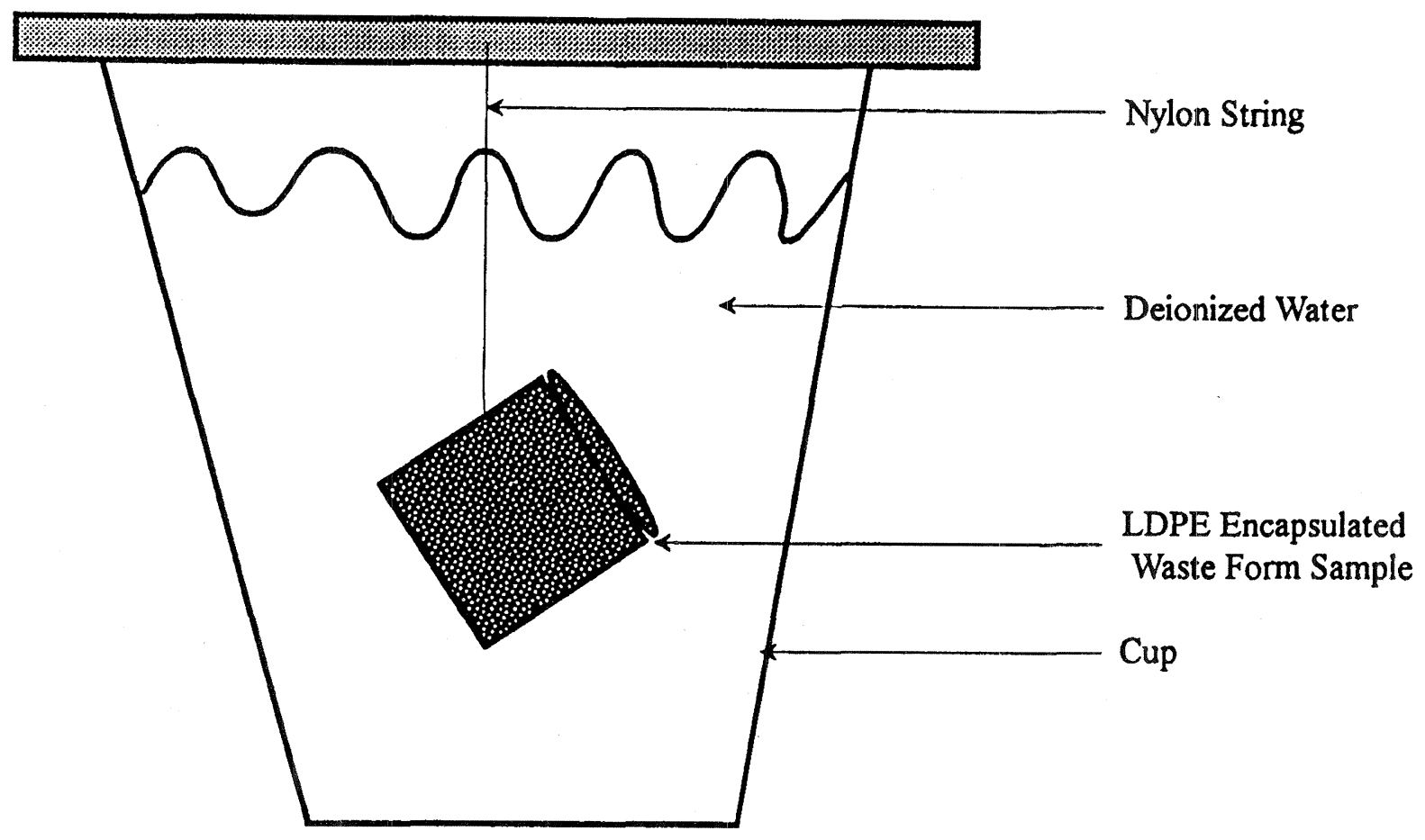


Figures A.1 and A.2 (see Appendix I) show the change in volume of cation (IRN-77) ion exchange resin during the 90-day water immersion test. The volume does not increase significantly for waste loadings $\leq 50 \mathrm{wt} \%$ because the tensile strength of the LDPE retards the swelling (see Section 2.0). Figures A.3 and A.4 show that the increase in weight of cation ion exchange resin waste forms due to water absorption is also most apparent for waste loadings above $50 \mathrm{wt} \%$.

The increase in volume for anion (IRN-78) ion exchange resin samples over the 90-day water immersion test are shown in Figures A.5 and A.6. The anion ion exchange resin encapsulated in LDPE have lower swelling properties than cation and show no increase in volume for waste loadings above $60 \mathrm{wt} \%$. Even samples with the maximum waste loading (70 $w t \%)$ swelled very little. The changes in weight over time for the anion ion exchange waste forms (Figures A.7 and A.8), follow the trend of the changes in its volume. Insignificant weight increases were measured for waste loadings $\leq 60 \mathrm{wt} \%$.

The trend in swelling and weight increases for encapsulated mixed bed (2:1 ratio) ion exchange resin waste forms over time (Figures A.9 - A.12) is similar to the anion ion exchange resin waste forms. No apparent increases in swelling or weight are observed for $\leq 60 w t \%$ and very small increases were observed for the $70 \mathrm{wt} \%$ anion ion exchange waste forms.

The results of this 90 -day water immersion test can be used to determine conservative formulations for which the pretreated ion exchange resin encapsulated in LDPE are stable under saturated disposal conditions. The average (samples A \& B) percent change in volume and weight over time (Figures 7.2 - 7.7) provides the basis for determining maximum and conservative waste loadings shown in Table 7.1. The maximum waste loading is considered to be the waste loading at which no catastrophic destruction occurred. Using the pretreatment and encapsulation process described, the maximum waste loading for the cation, anion, and mixed bed ion exchange resin is $70 \mathrm{wt} \%$. Cation, anion, and mixed bed ion exchange resin waste forms with waste loadings below their respective conservative recommended waste loadings, remained stable with regard to changes in weight or volume over time. 
Table 7.1: Maximum and Conservative waste loadings obtained, using 90-day water immersion test, for thermally pretreated ion exchange resin in LDPE

\begin{tabular}{|c|c|c|}
\hline Resin Type & $\begin{array}{c}\text { Maximum } \\
\text { Waste Loading (wt \%) }\end{array}$ & $\begin{array}{c}\text { Conservative } \\
\text { Waste Loading (wt \%) }\end{array}$ \\
\hline Cation (IRN-77) & 70 & 50 \\
\hline Anion (IRN-78) & 70 & 60 \\
\hline $\begin{array}{c}\text { Mixed Bed } \\
\text { cation : 1 anion ratio) }\end{array}$ & 70 & 60 \\
\hline
\end{tabular}


Figure 7.2: Average (Samples A and B) \% Change In Weight, vs. Time (Days)

for Pretreated Cation (IRN-77) Ion Exchange Resin Immersed in Delonized Water

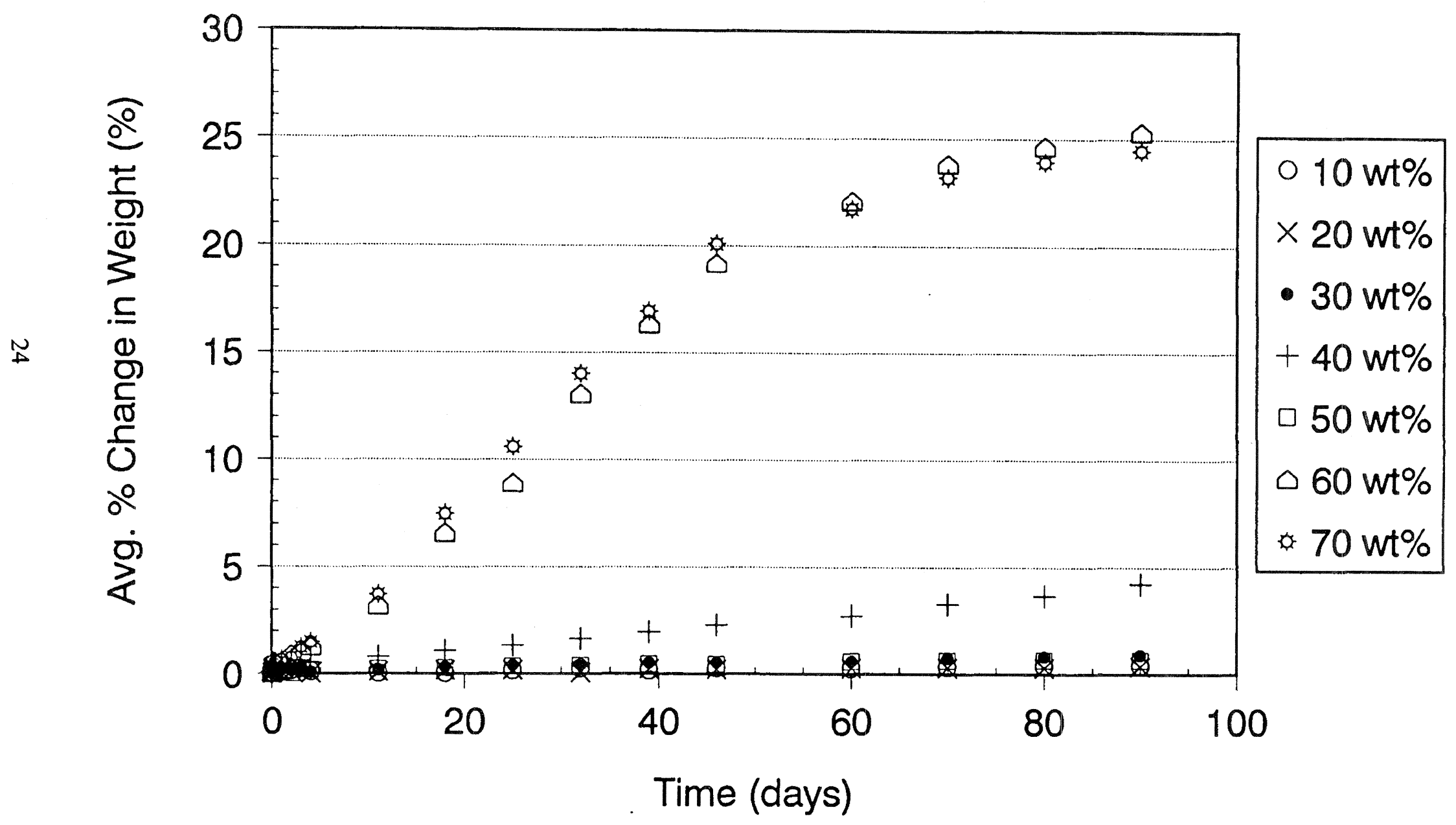


Figure 7.3 : Average (Samples A and B) \% Change in Weight, vs. Tme (Days)

for Pretreated Anion (IRN-78) Ion Exchange Resin Immersed in Deionized Water

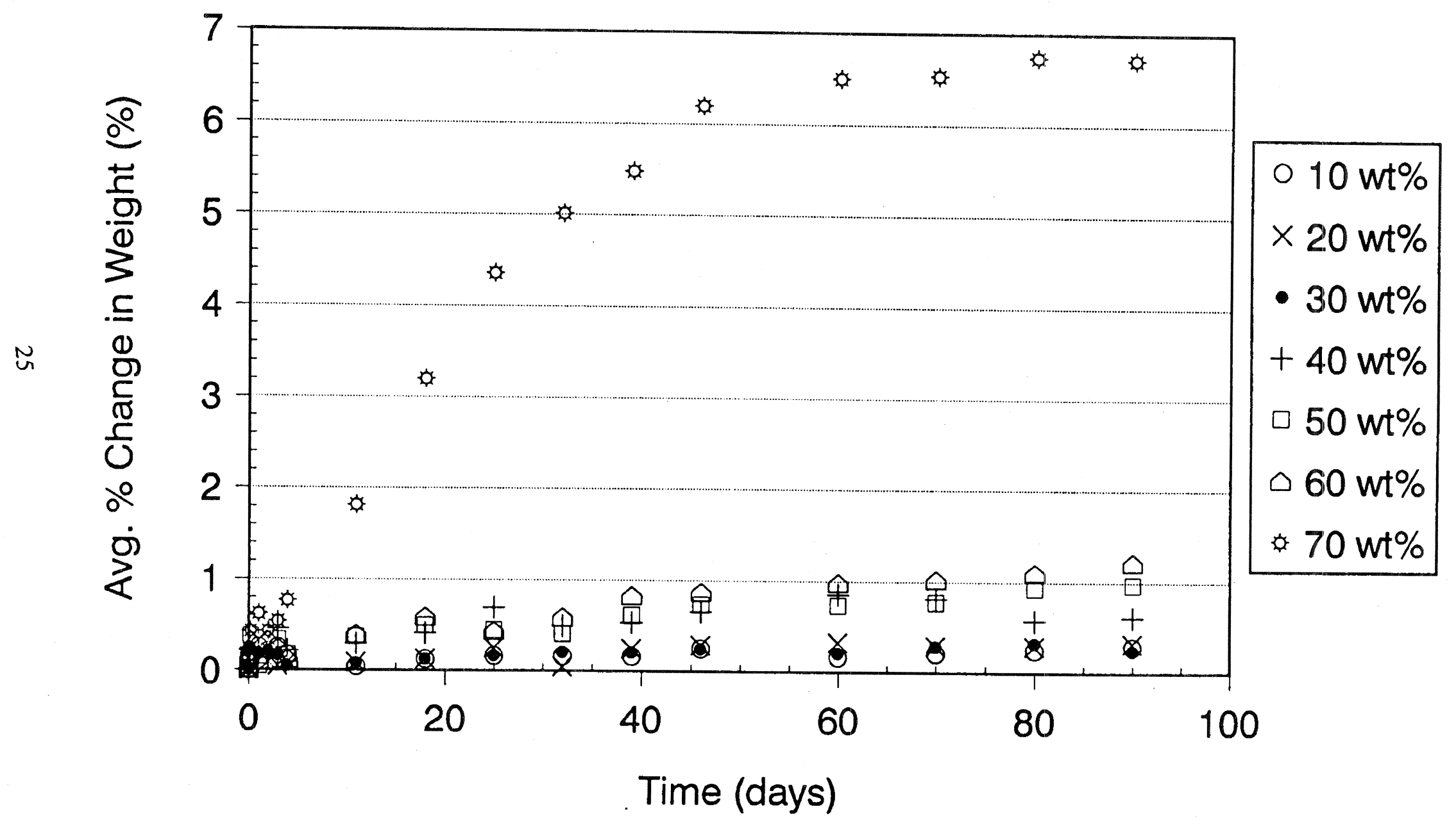


Figure 7.4: Average (Samples A and B) \% Change In Weight, vs. Time (Days) for Pretreated Mixed Bed (2:1 ratio) lon Exchange Resin Immersed In Deionized Water

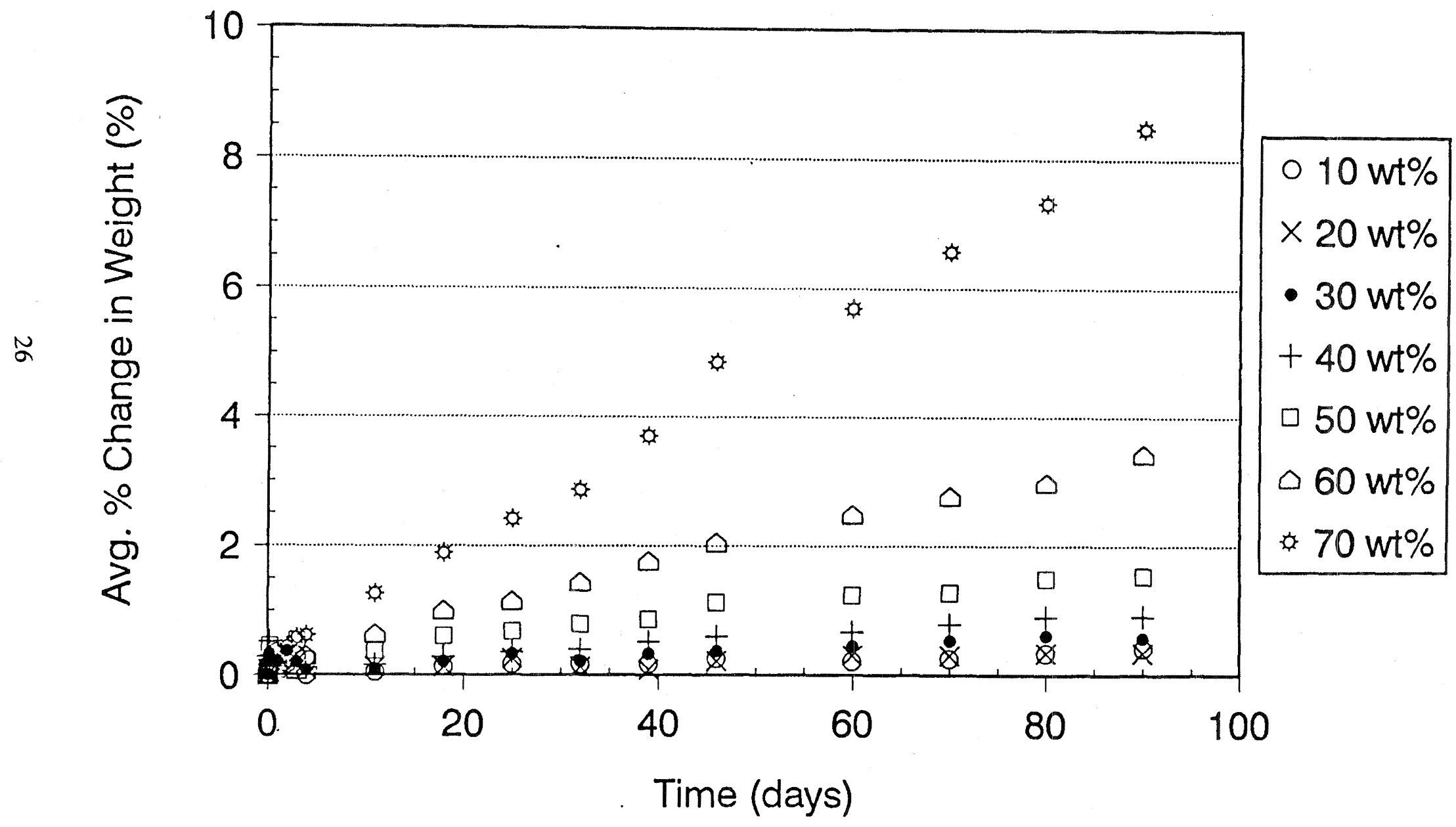


Figure 7.5: Average (Samples A and B) \% Change in Volume, vs. Time (Days) for Pretreated Cation (IRN-77) Ion Exchange Resin Immersed in Deionized Water

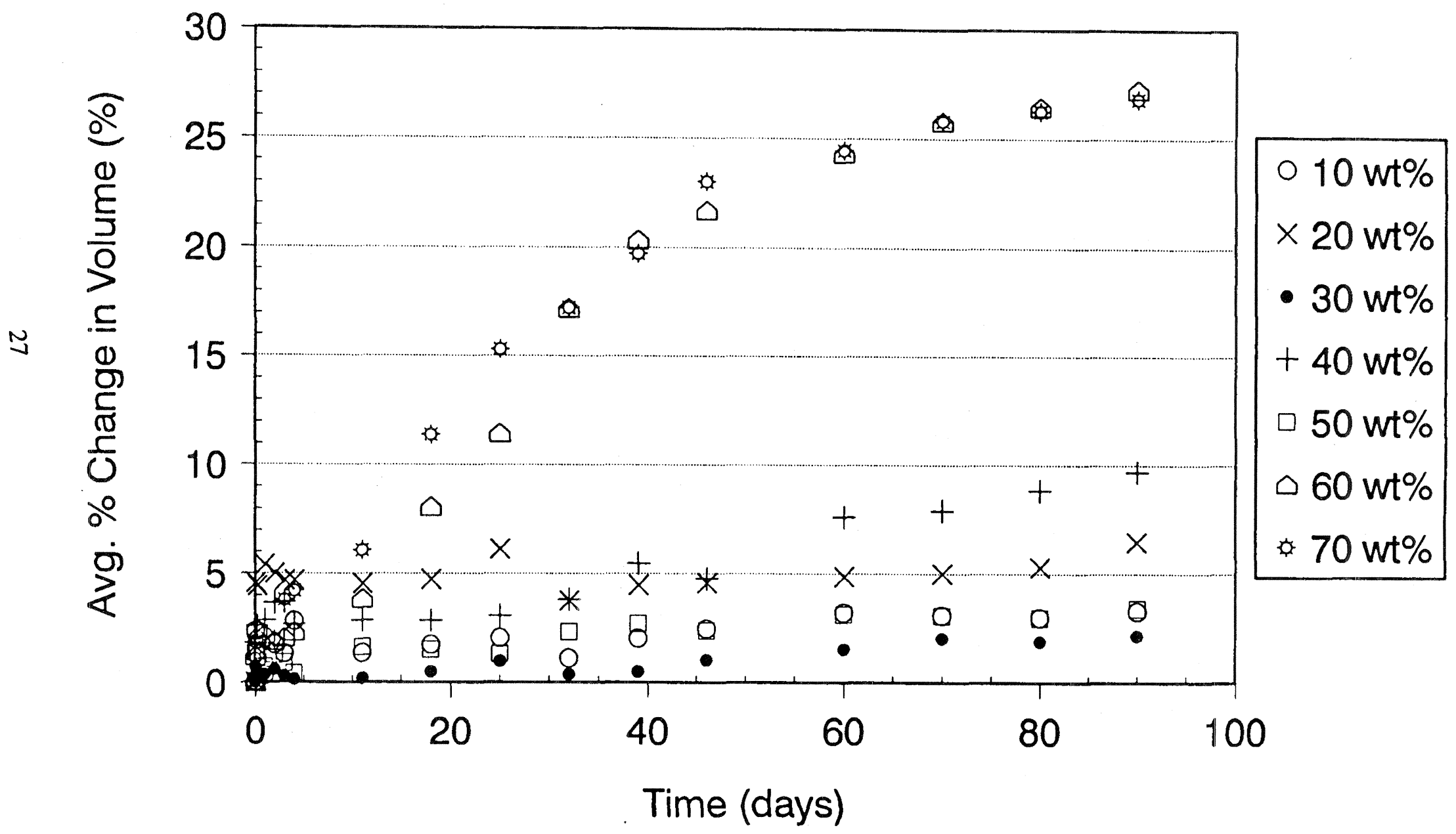


Figure 7.6: Average (Samples A and B) \% Change in Volume, vs. Time (Days) for Pretreated Anion (IRN-78) lon Exchange Resin Immersed in Deionized Water

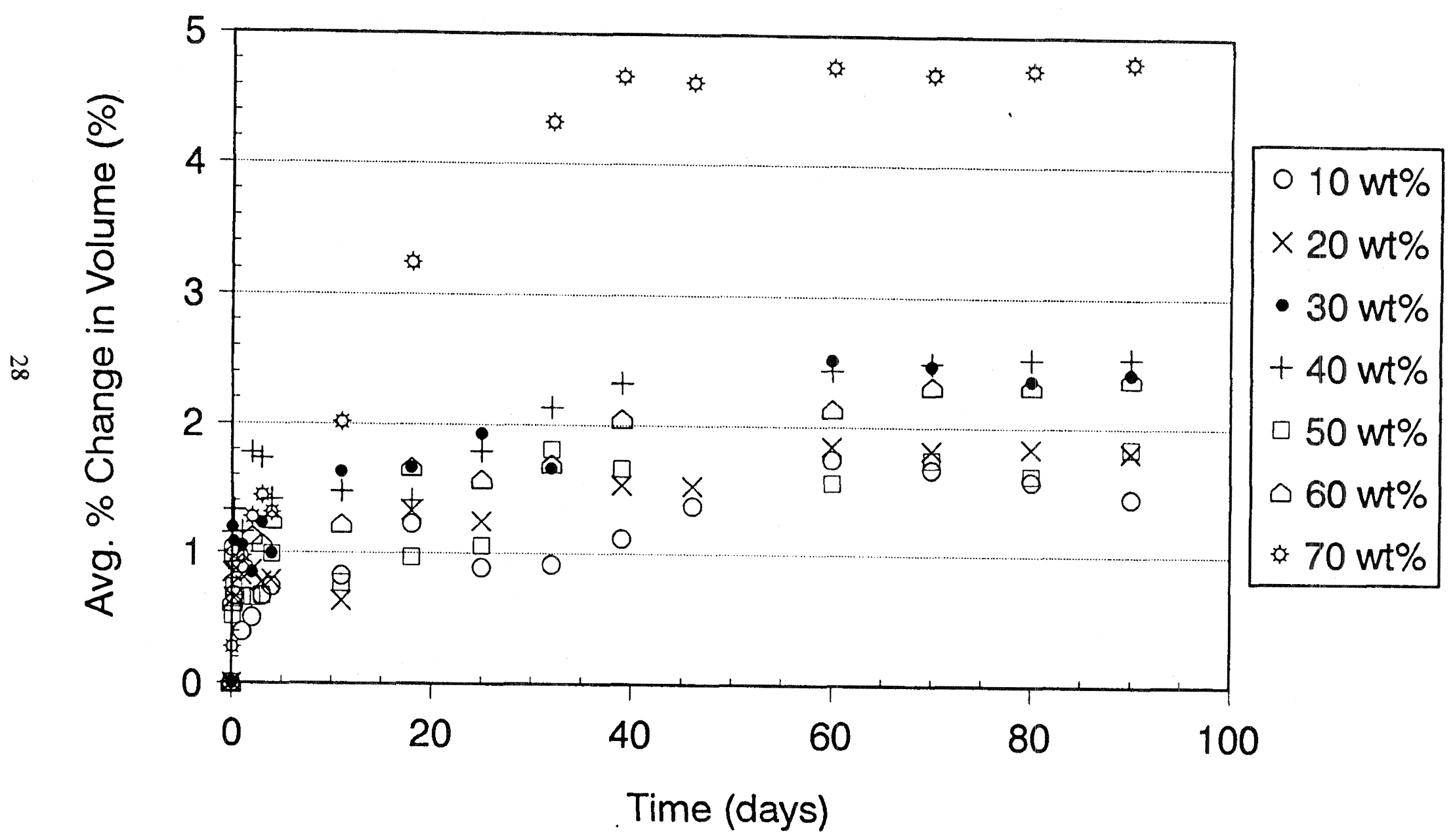


Figure 7.7: Average (Samples A and B) \% Change in Volume, vs. Time (Days) for Pretreated Mixed Bed (2:1 ratio) Ion Exchange Resin Immersed in Deionized Water

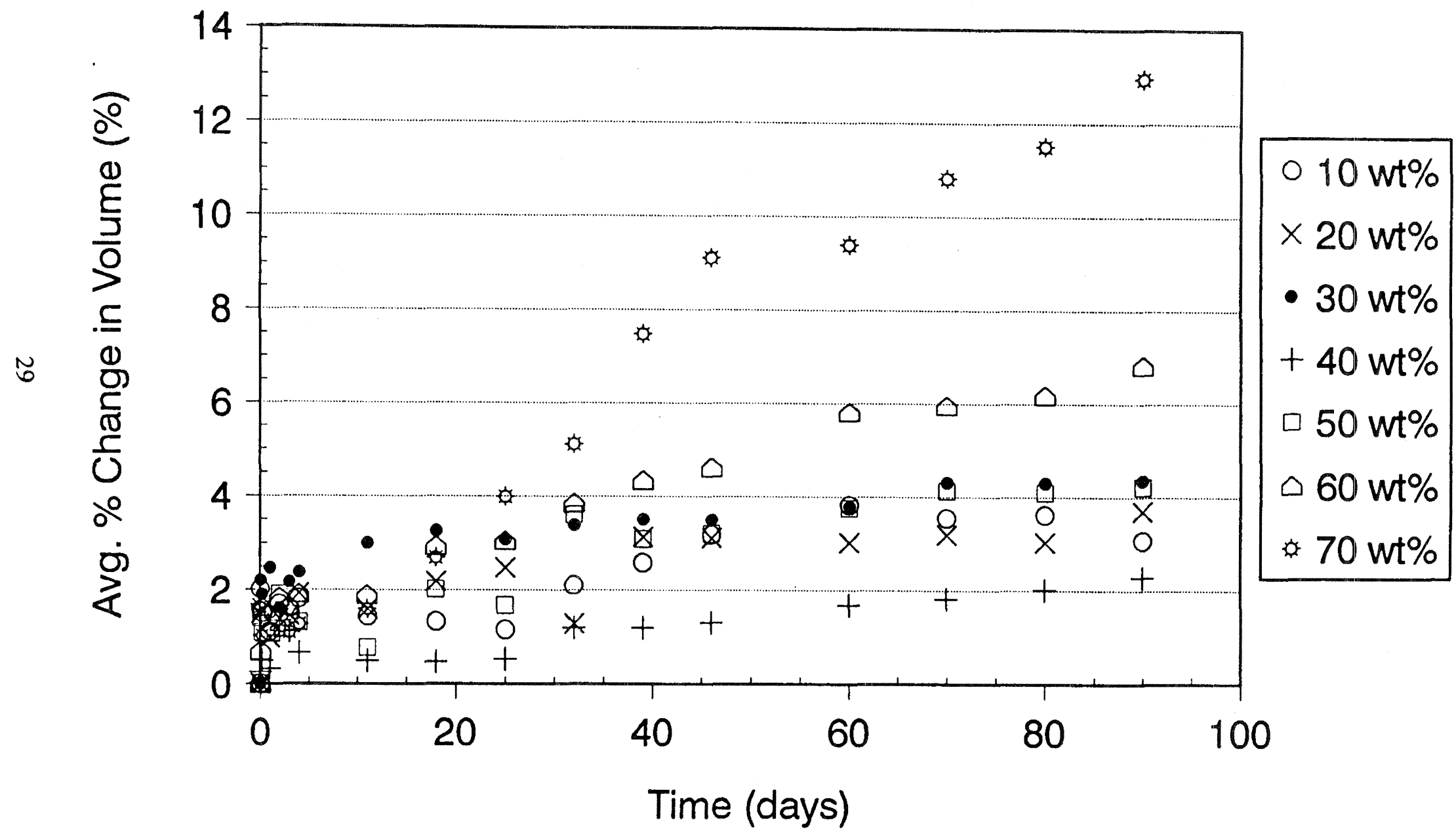




\subsection{CONCLUSION}

The combination of thermal pretreatment and LDPE extrusion has been successfully demonstrated for the encapsulation of ion exchange resin. The waste forms produced did experience changes in dimension and weight, but no structural destruction of the waste form, as observed with cement [2] and LDPE encapsulation process without pretreatment [5], occurred. The following conclusions may be drawn as a result of this investigation:

○ Thermal pretreatment (@300 oC for 1 hour in conventional oven) reduced the swelling properties of anion and cation ion exchange resin.

- Thermal pretreatment decreases the swelling properties of anion resin more than cation resin.

0 The maximum waste loadings (wt \%) recommended for encapsulation of cation, anion, and mixed bed (2:1 ratio) ion exchange resin is $70 \mathrm{wt} \%$.

- The conservative waste loadings ( $w t \%)$ recommended for encapsulation of cation ion exchange resin is $50 \mathrm{wt} \%$ and for anion and mixed bed ion exchange resins is 60 wt $\%$.

Future research and development efforts are required to obtain more detailed information on performance of LDPE encapsulated ion exchange resin waste forms, following thermal pretreatment. 


\section{REFERENCES}

[1] McCoy, S.B., "Advances in the Disposal of Radioactive Ion Exchange Resins", Proceedings of Waste Management '83, Vol. 1, p.327-329.

[2] Neilson, R.M. and Colombo, P., Solidification of Ion Exchange Resin Wastes, BNL-51615, Brookhaven National Laboratory, Upton, NY, August 1982.

[3] International Atomic Energy Agency (IAEA), Treatment of Spent Ion-Exchange

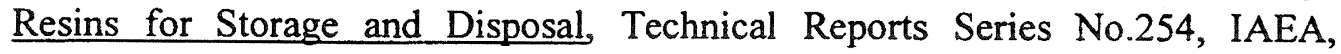
Vienna (1985).

[4] Kunin, R., Ion Exchange Resins, Robert E. Kerieger Publishing Co., Huntingtion, NY, 1972.

[5] Helfferich, F., Ion Exchange, McGraw-Hill, New York, NY, 1972.

[6] Gregor, H. P., "A General Thermodynamic Theory of Ion Exchange Processes", Am. Chem. Soc., 70, 1293 (1948).

[7] Matsuda, M., Nishi, T., Chino, K., and Kikuchi, M., "Solidification of Spent Ion Exchange Resin Using New Cementitious Material, (I) Swelling Pressure of Ion Exchange Resins", J. of Nucl. Sci. and Tech., Vol. 29, No. 9, p.883-889, Nov. 1992.

[8] Kalb, P. D., and Colombo, P., Polyethylene Solidification of Low-Level Wastes, Topical Report, BNL-51867, Brookhaven National Laboratory (BNL), Upton, NY, Oct. 1984.

Matsuda, N., Nishi, T., and Kikuchi, M., "Soldification of Spent Ion Exchange Resin Using New Cementitious Material, (II), Improvement of Resin Content by Fiber Reinforced Cement", J. of Nucl. Sci. and Tech., Vol. 29, No.11, p.10931099, Nov. 1992.

[10] Moghissi, A. A., Godbee, H. W., and Hobart, S. A., Radioactive Waste Technology, American Society of Mechanical Engineers, New York, NY, 1992.

[11] Barnhart, V., and Gussman, H., "Incineration of Low-Level Radioactive Waste and Ion Exchange Resins", Proceedings of Waste Management '84, Vol.2, p.227-230. 


\section{REFERENCES (continued)}

[12] Farinoso, F., Deltete, C., and Wilson, R., "Spent Resin Incineration: Should Radioactivity Preclude it?", Proceedings of Waste Management '84, Vol.2, p.219-222.

[13] Yim, S. P., Kim, J., Park, H. H., Suh, I. S., "The Effect of Quick Freeze Pretreatment on Grinding of Spent Organic Ion Exchange Resins", Proceedings of Waste Management '91, Vol. 2, p.295-298.

[14] ASTM, Standard Method of Test for Physical and Chemical Properties of Ion Exchange Resins, D2187-77, American Society for Testing and Materials, Philadelphia, PA, 1975.

[15] USNRC, "Technical Position on Waste Form", US Nuclear Regulatory Commission, Low-Level Waste Licensing Branch, Washington, DC, May 1983. 


\section{APPENDIX I}

Plots of Changes in Volume and Weight for Ion Exchange Waste Forms Immersed in Water. 
Figure A.1: Volume (cu. cm) of Sample A, measured using a caliper, vs. Time (Days) for Pretreated Cation (IRN-77) Ion Exchange Resin Immersed in Deionized Water

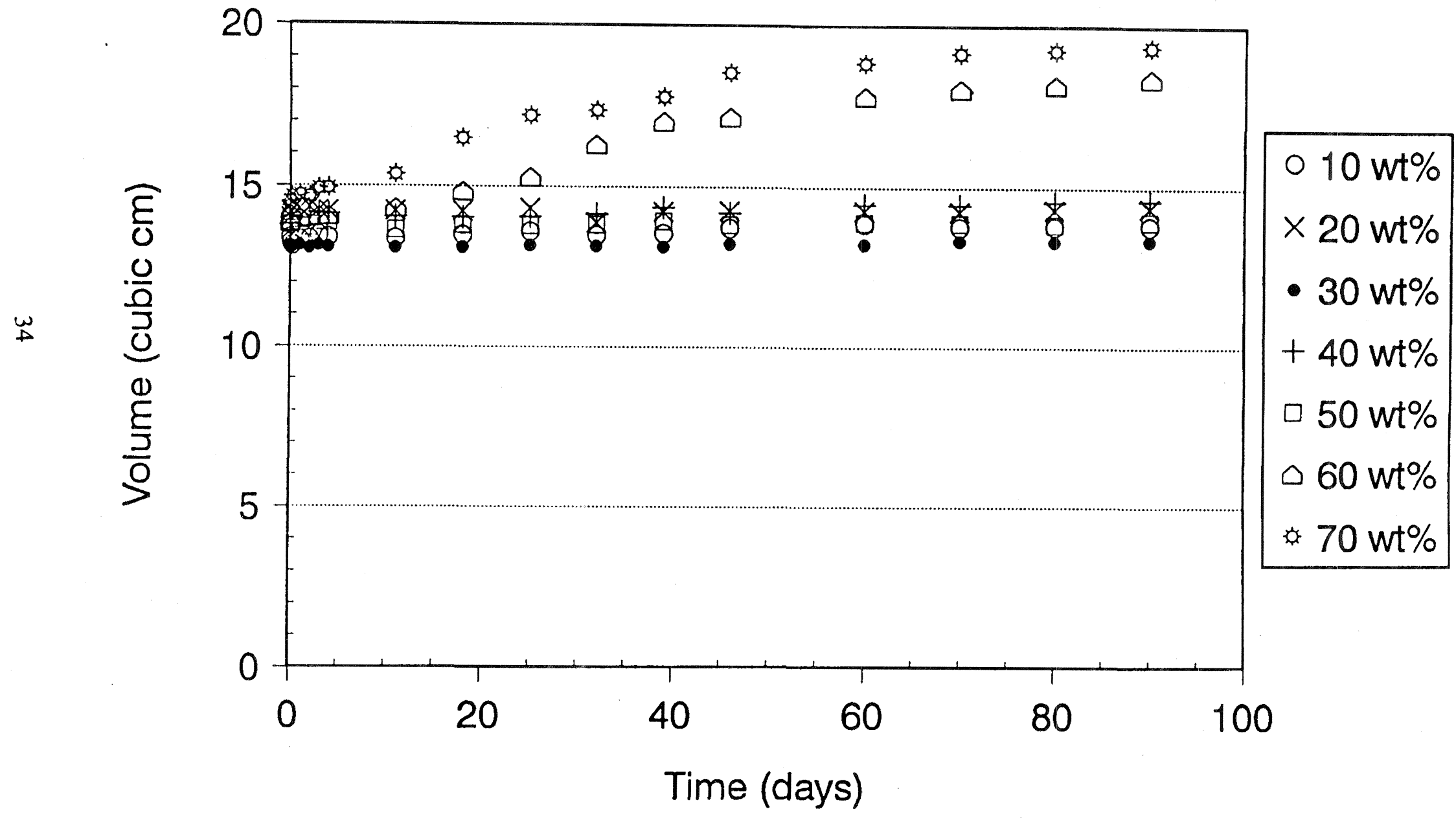


Figure A.2: Volume (cu. $\mathrm{cm}$ ) of Sample B, measured using a Caliper, vs. Time (Days) for Pretreated Cation (IRN-77) Ion Exchange Resin Immersed in Deionized Water

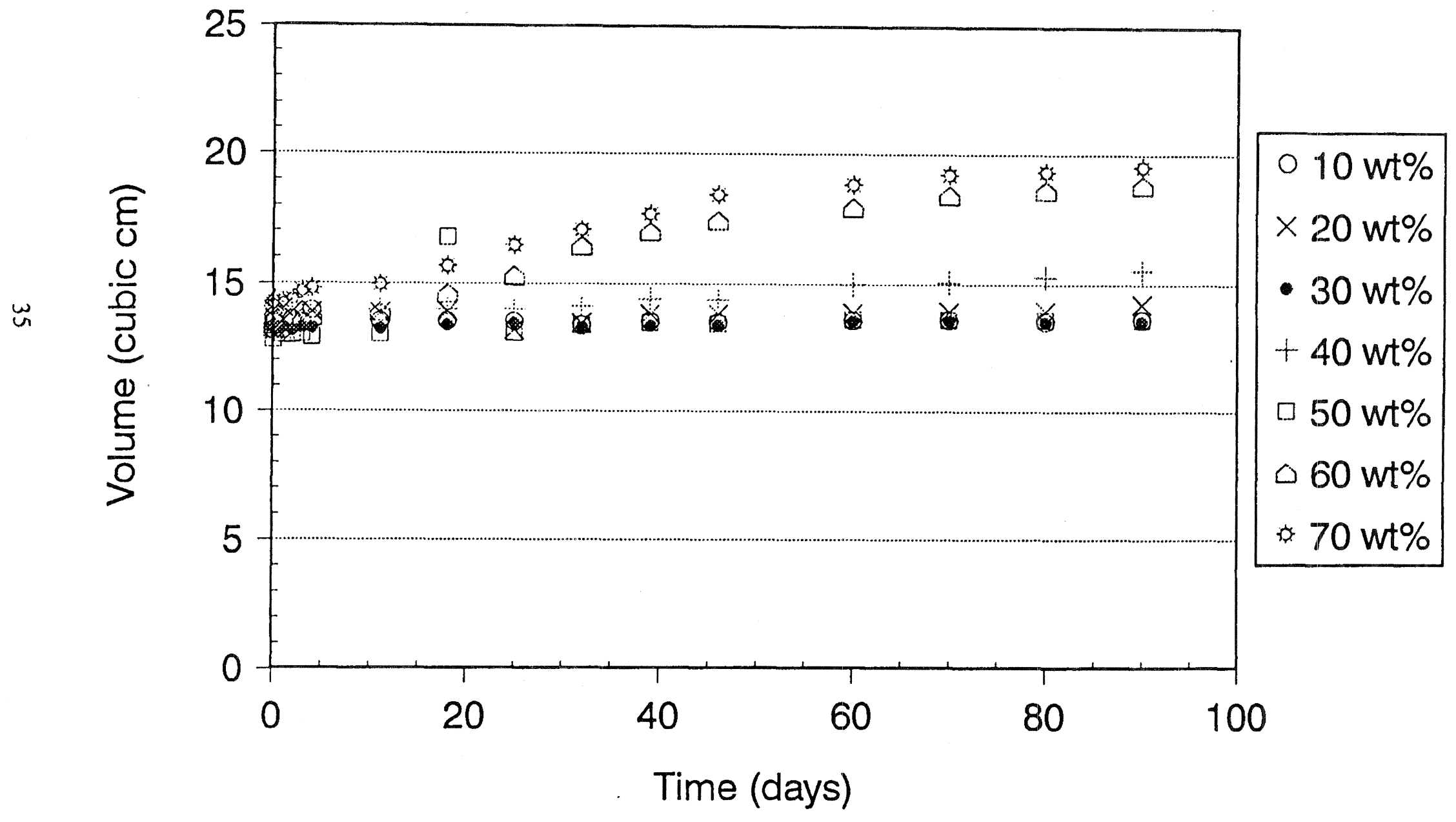


Figure A.3: Weight (grams) of Sample A vs. Time (Days) for Pretreated Cation (IRN-77) Ion Exchange Resin Immersed In Deionized Water

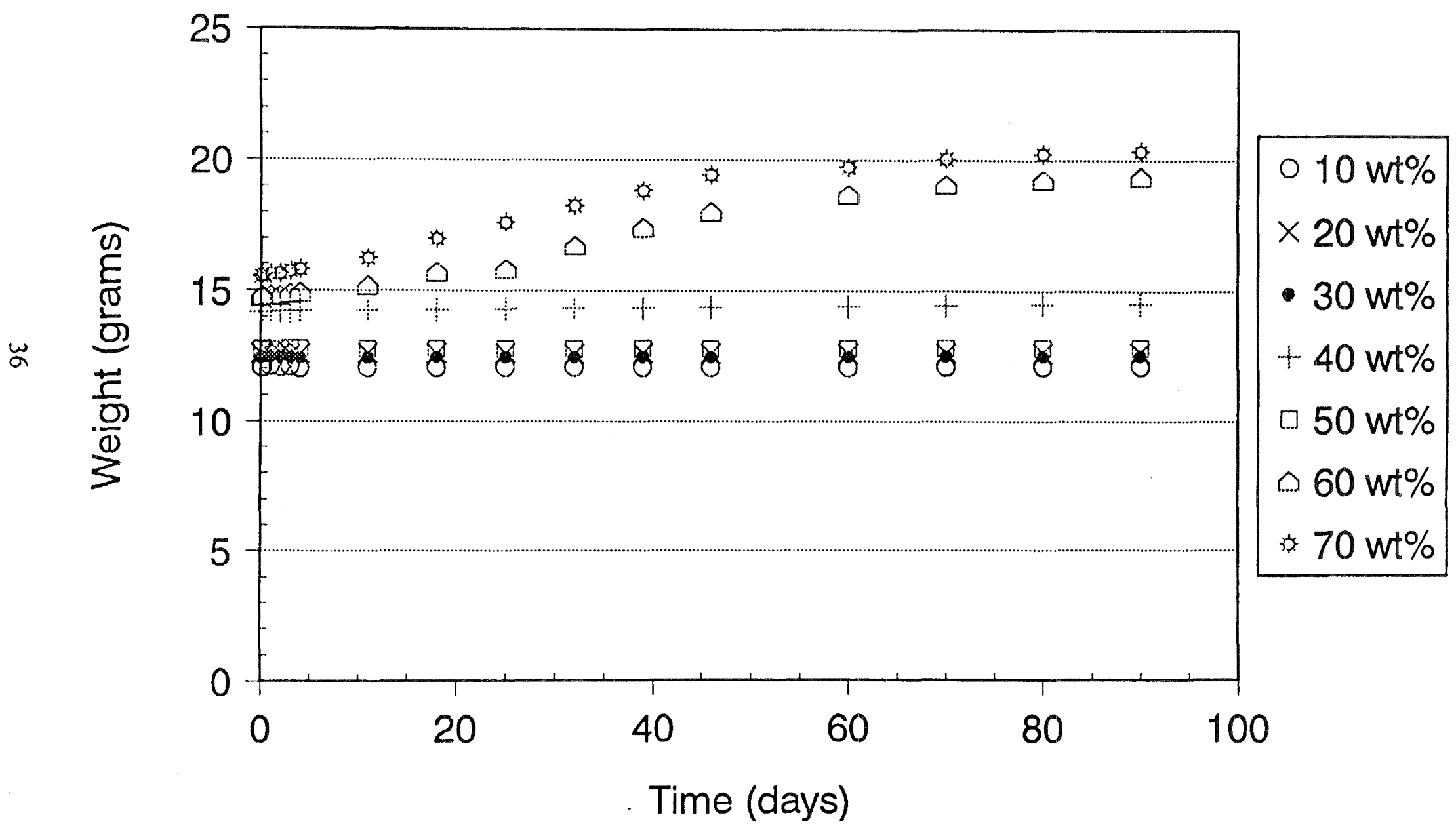


Figure A.4: Weight (grams) of Sample B vs. Time (Days) for Pretreated Cation (IRN-77) Ion Exchange Resin Immersed in Deionized Water

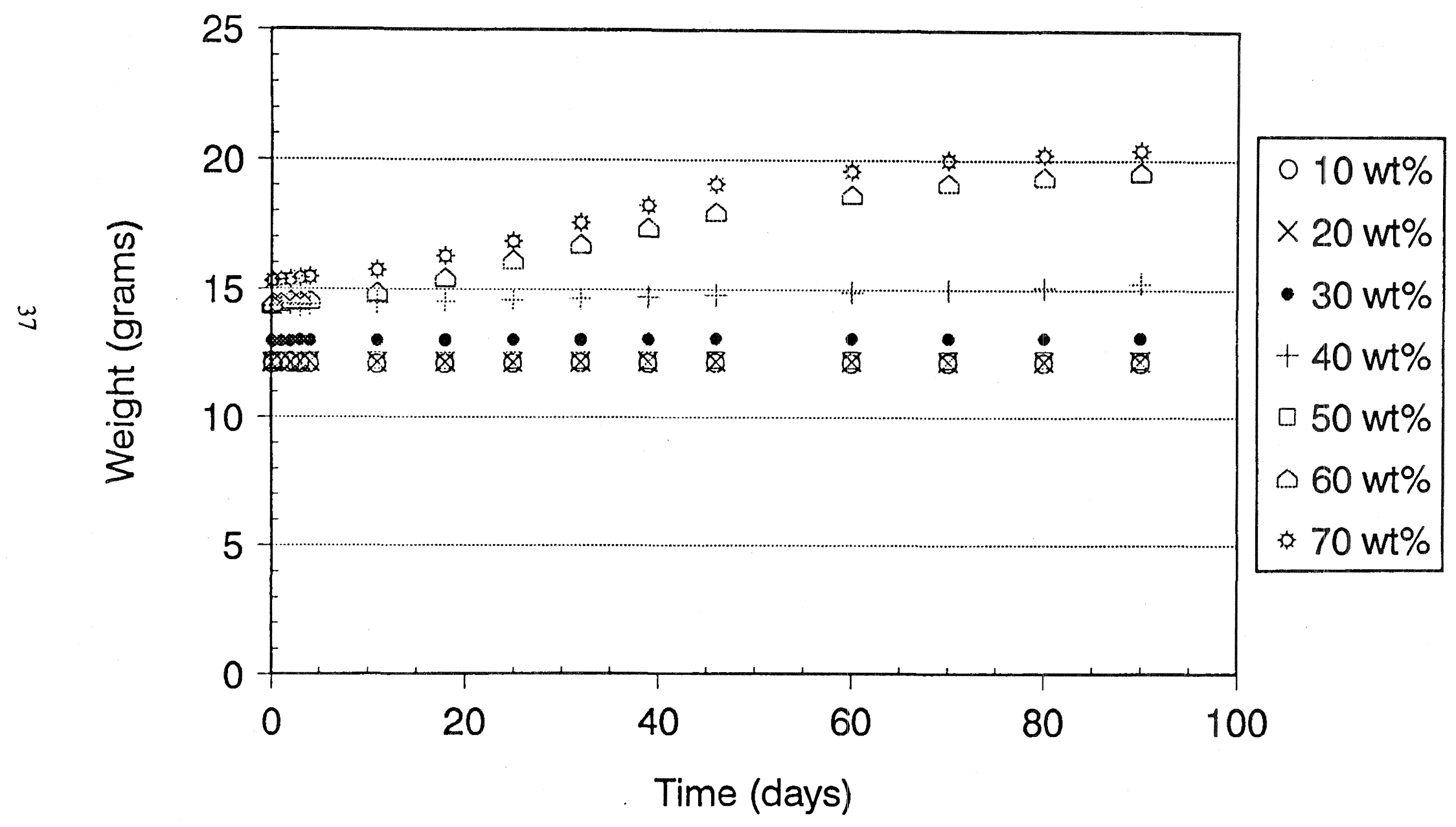


Figure A.5: Volume (cu. cm) of Sample A, measured using a caliper, vs. Time (Days) for Pretreated Anion (IRN-78) Ion Exchange Resin Immersed in Deionized Water

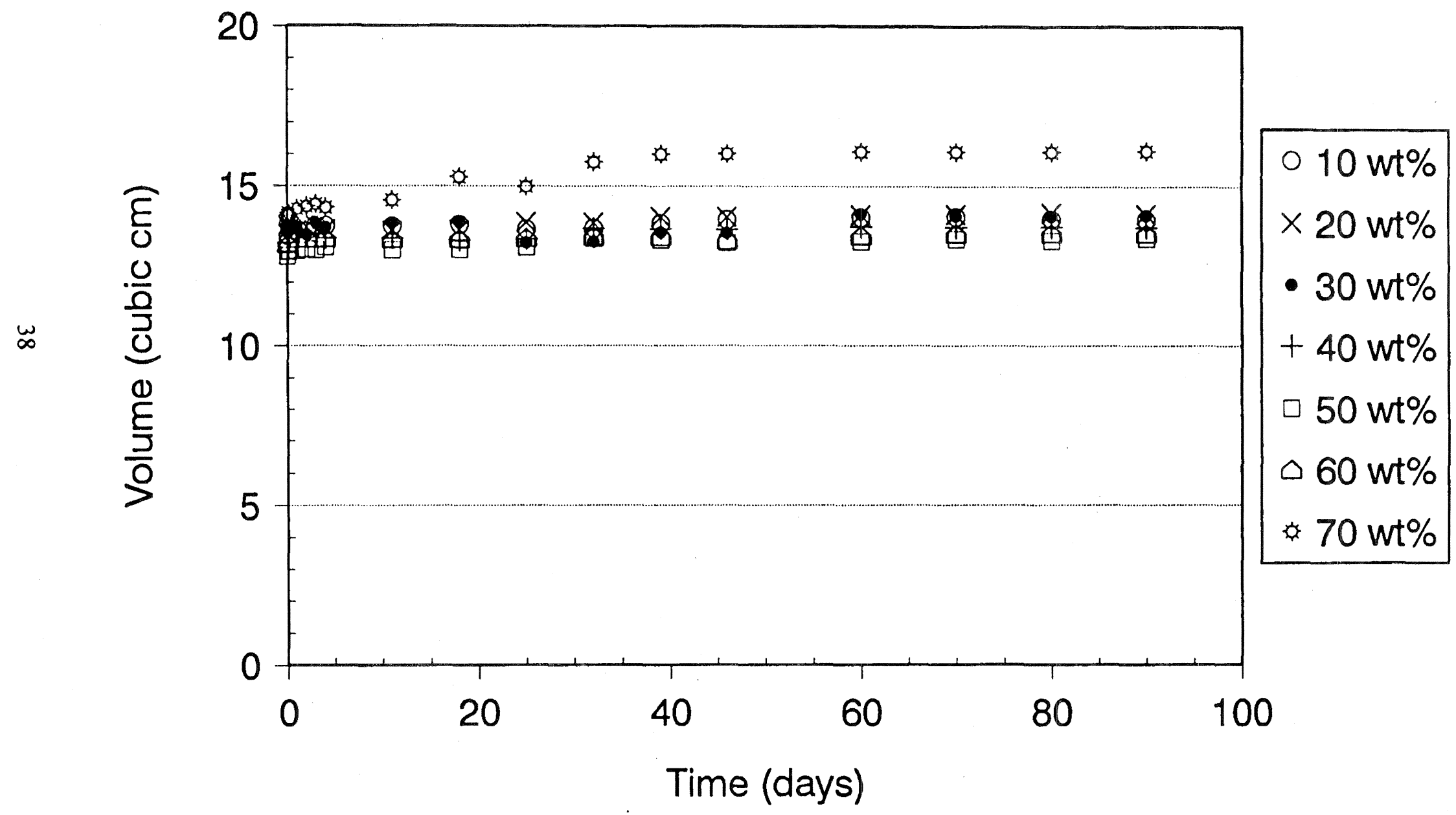


Figure A.6: Volume (cu. $\mathrm{cm}$ ) of Sample B, measured using a Caliper, vs. Time (Days) for Pretreated Anion (IRN-78) Ion Exchange Resin Immersed in Deionized Water

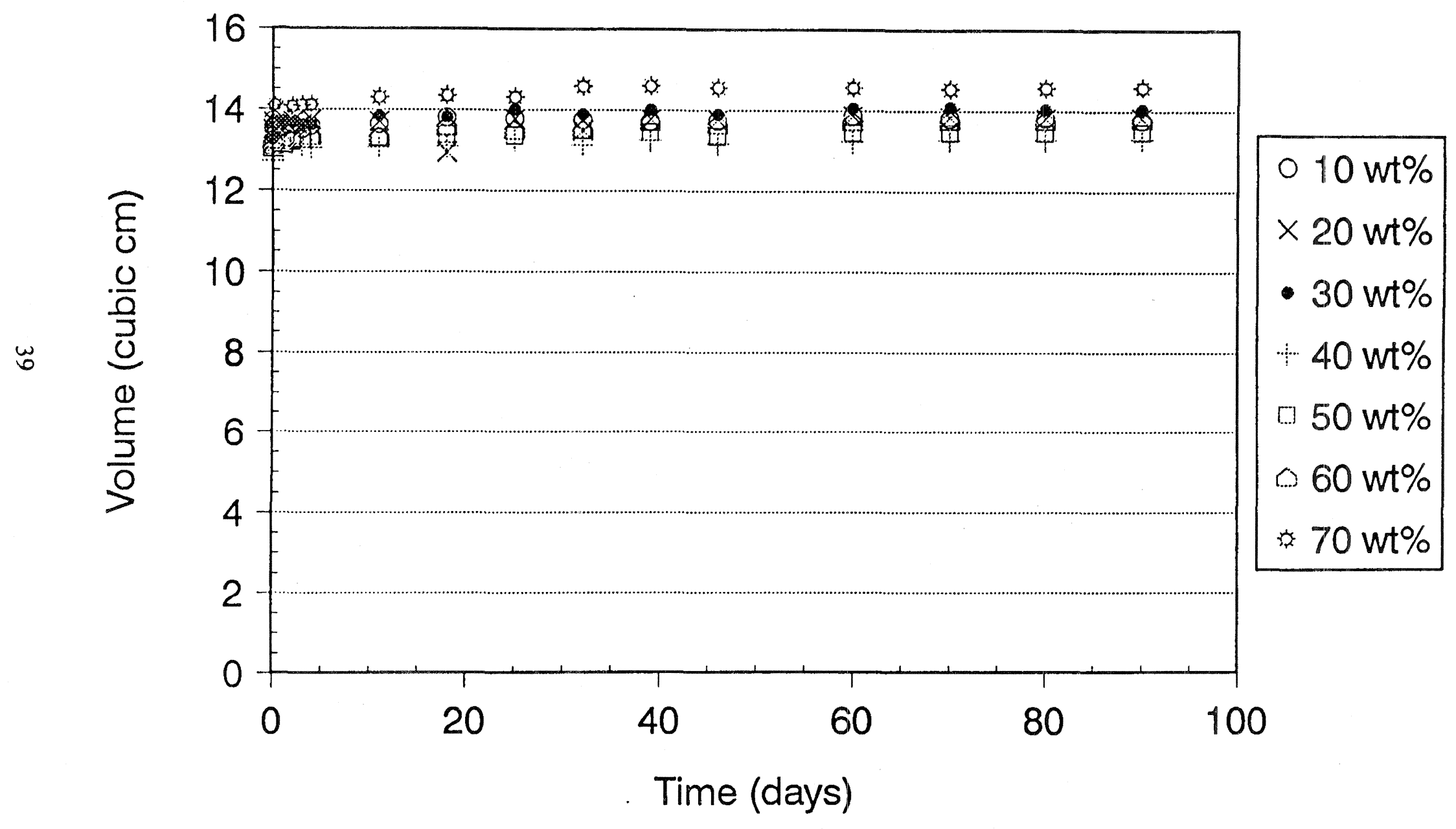


Figure A.7: Weight (grams) of Sample A vs. Time (Days) for Pretreated

Anion (IRN-78) Ion Exchange Resin Immersed in Deionized Water

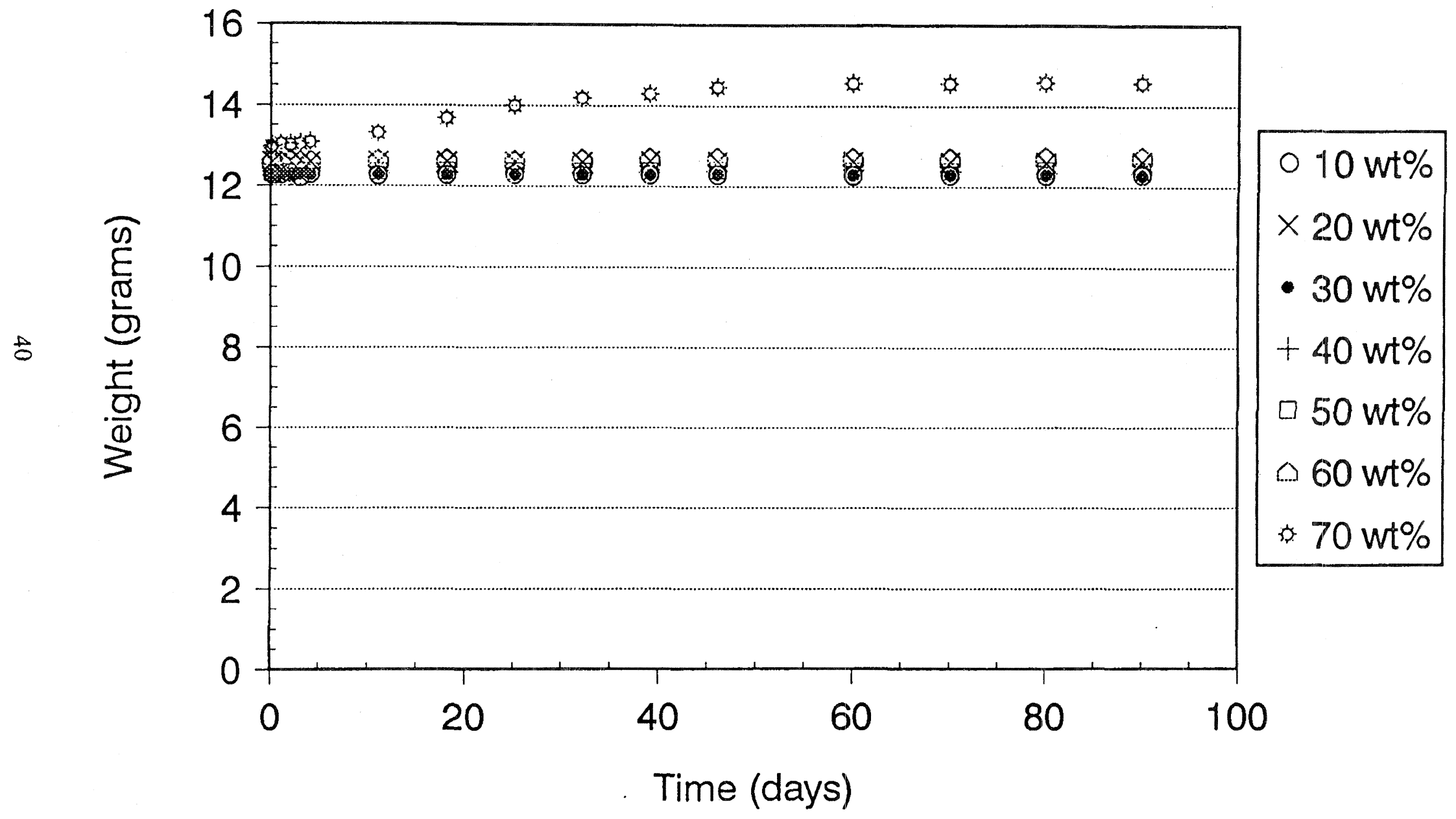


Figure A.8: Weight (grams) of Sample B vs. Time (Days) for Pretreated

Anion (IRN-78) Ion Exchange Resin Immersed in Delonized Water

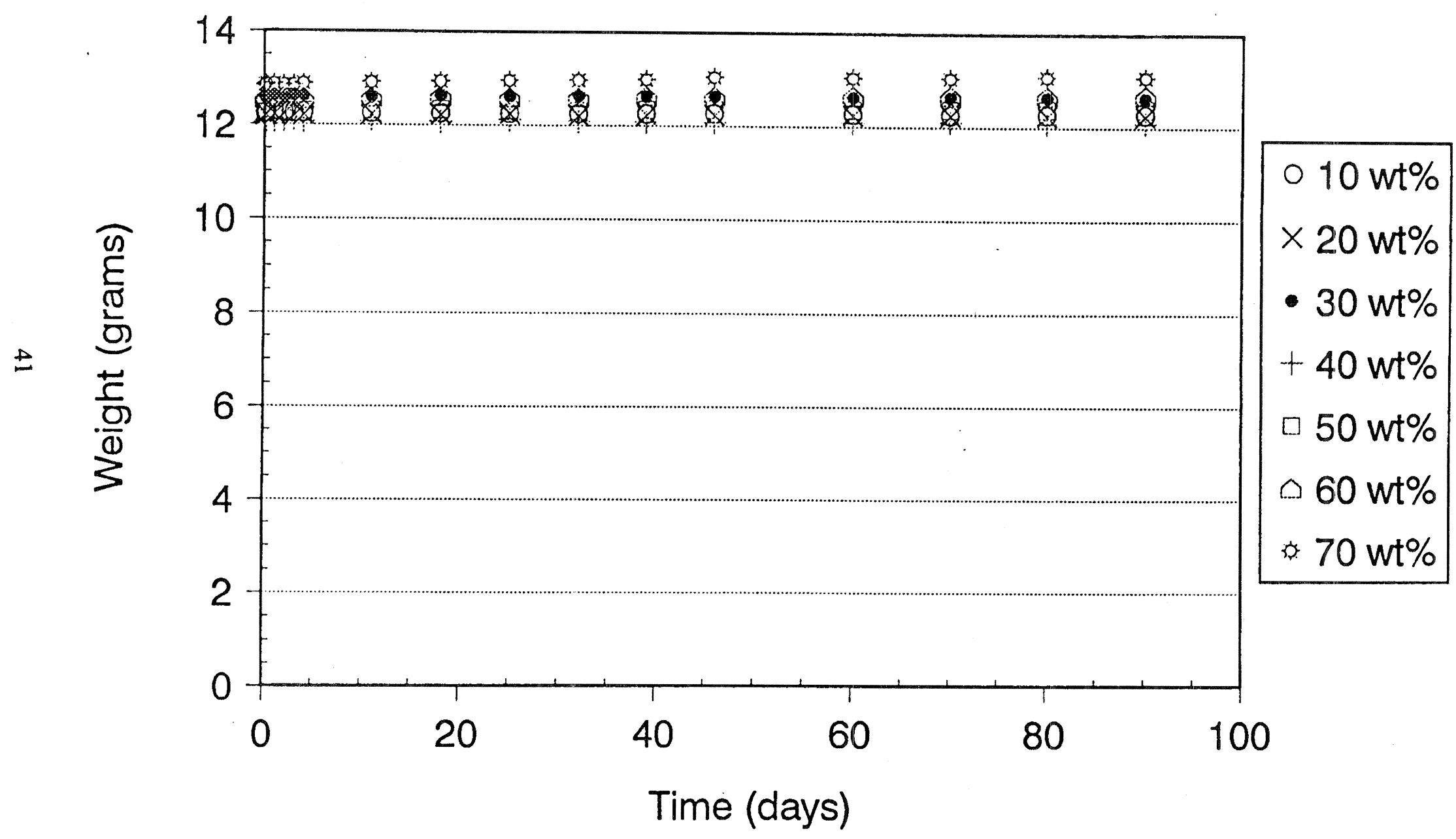


Figure A.9: Volume (cu. $\mathrm{cm}$ ) of Sample A, measured using a Caliper, vs. Time (Days) for

Pretreated Mixed Bed (2:1 ratio) lon Exchange Resin Immersed in Deionized Water

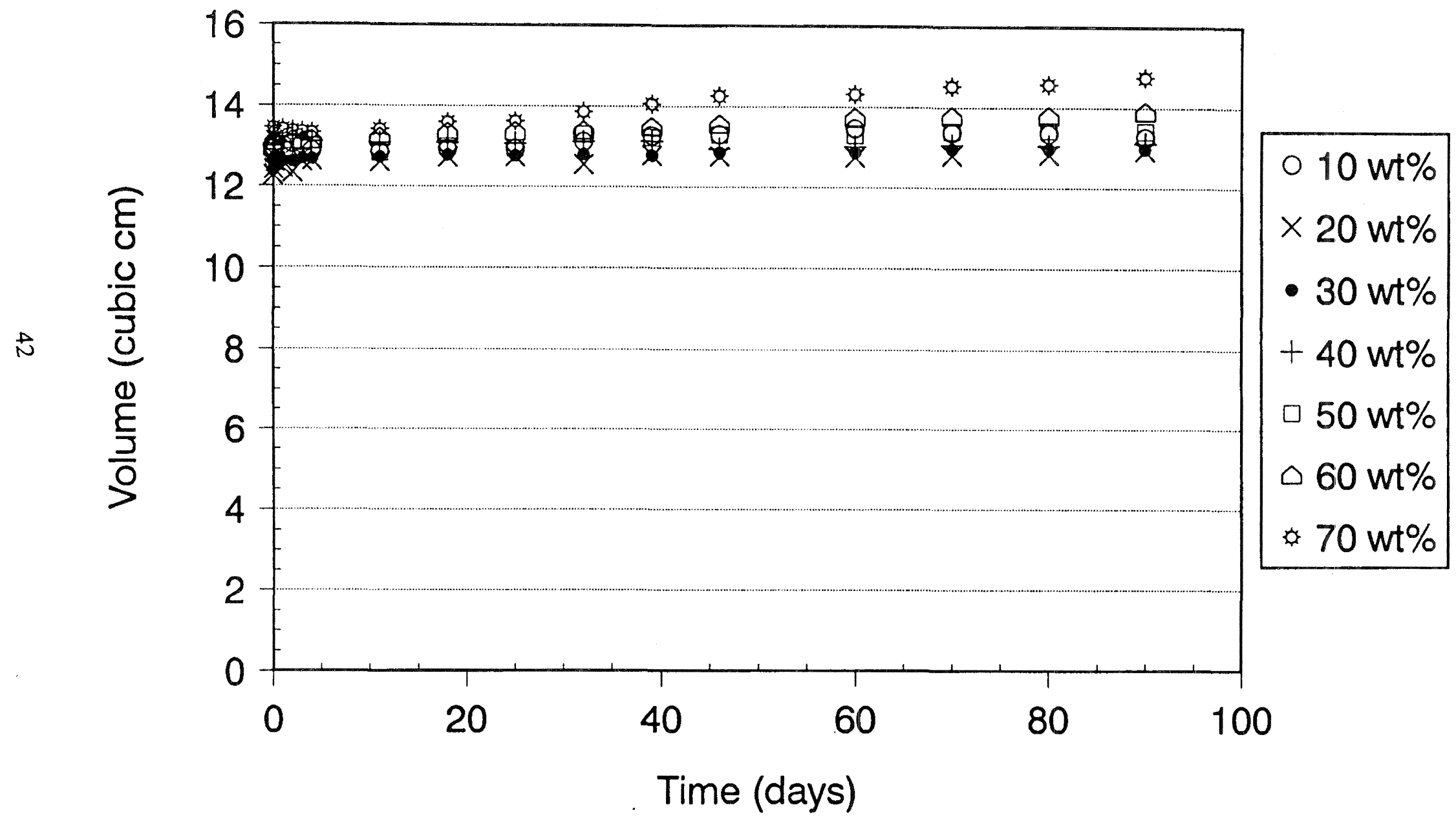


Figure A.10: Volume (cu. cm) of Sample B, measured using a Caliper, vs. Time (Days) for Pretreated Mixed Bed (2:1 ratio) Ion Exchange Resin Immersed in Delonized Water

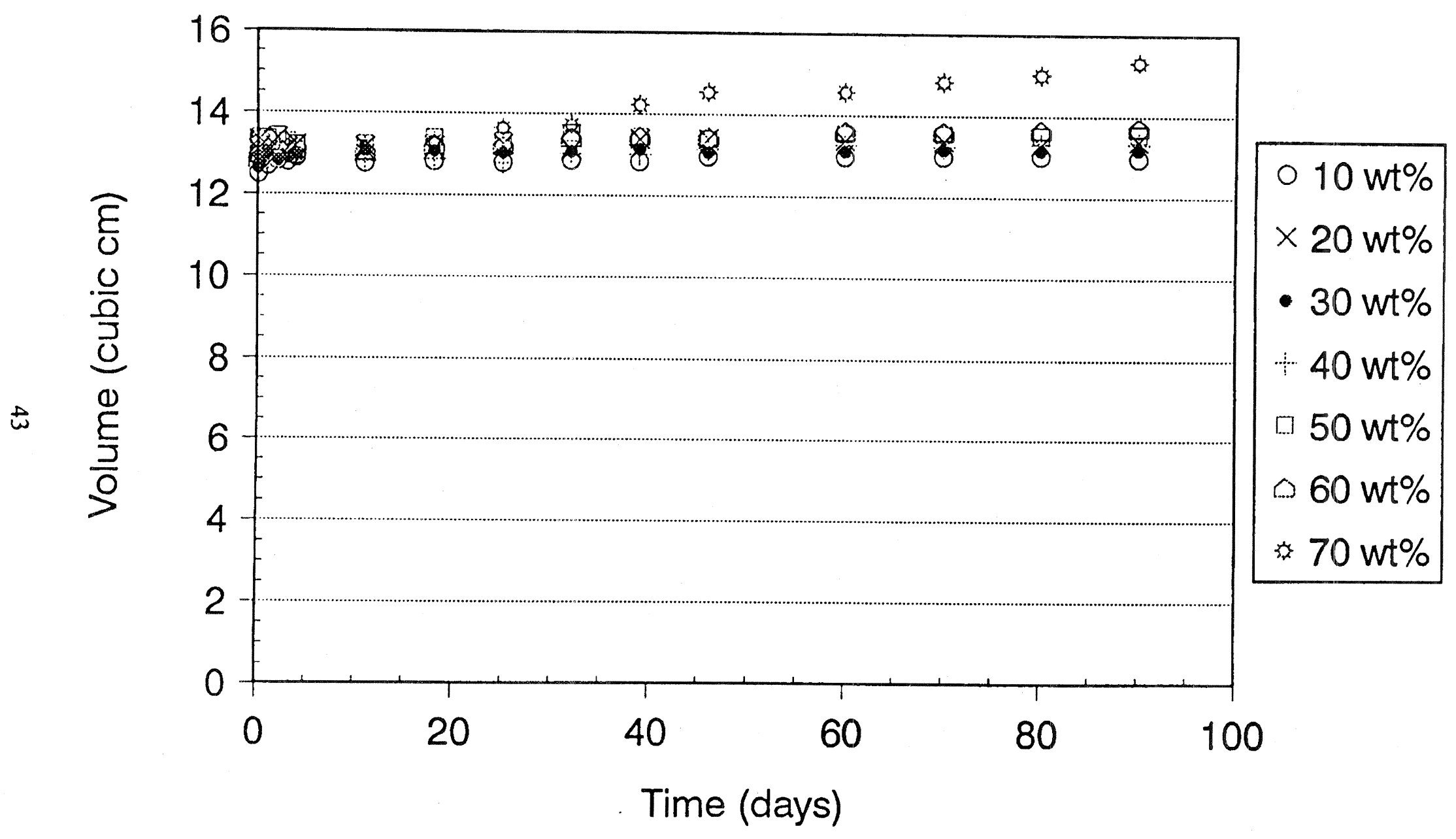


Figure A.11: Weight (grams) of Sample A vs. Time (Days) for Pretreated Mixed Bed (2:1 ratio) Ion Exchange Resin Immersed in Delonized Water

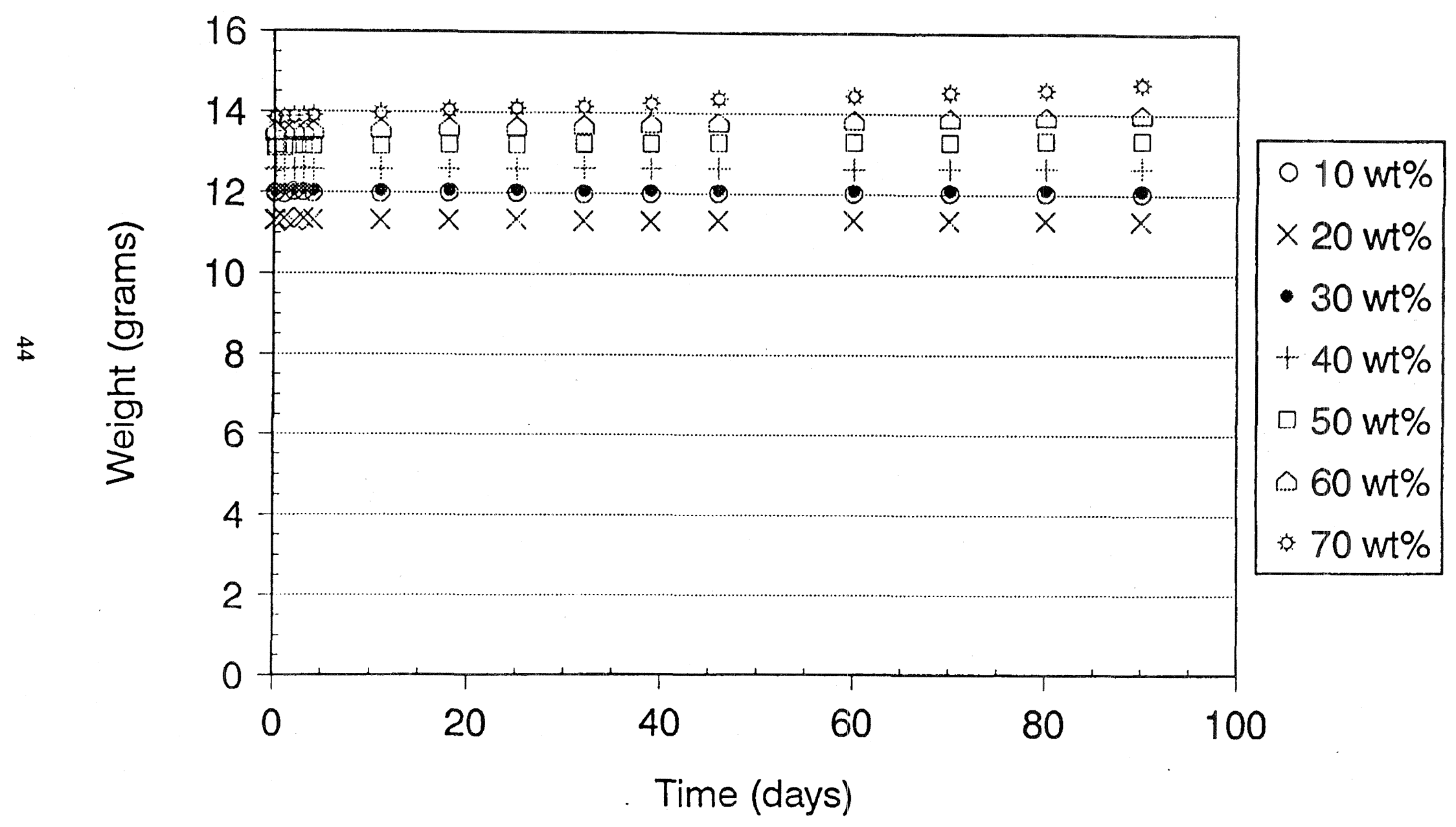


Figure A.12: Weight (grams) of Sample B vs. Time (Days) for Pretreated Mixed Bed (2:1 ratio) lon Exchange Resin Immersed in Delonized Water

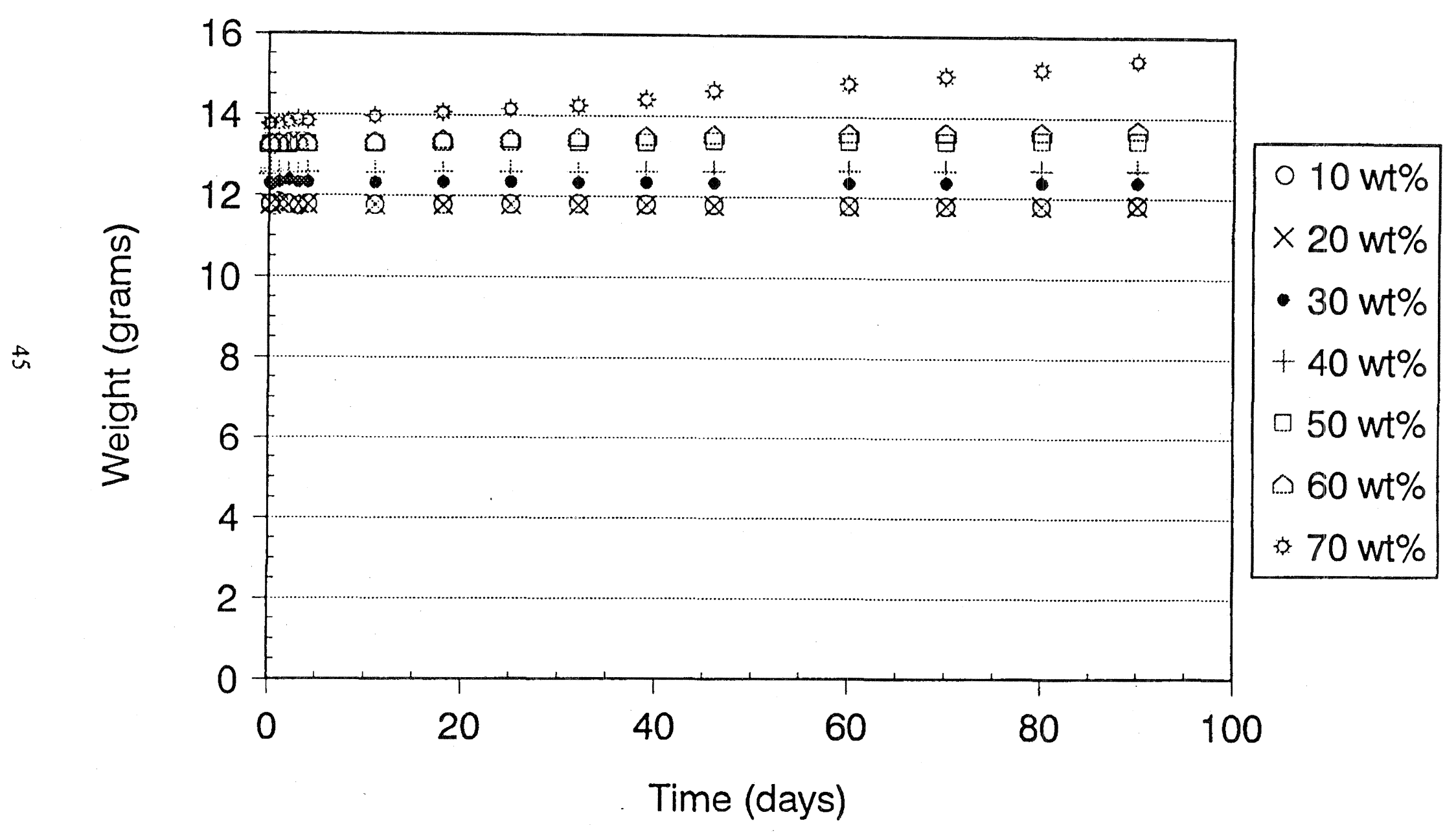




\section{APPENDIX II}

Data Collected for Changes in Volume and Weight of Ion Exchange Resin Waste Forms. 
Table A.1: Volume Measurements Using a Caliper for Cation (IRN-77), Sample A, Ion Exchange Resin

\begin{tabular}{|c|c|c|c|c|c|c|c|}
\hline Time (Days) & Vol. $10 \mathrm{w} \%\left(\mathrm{~cm}^{\wedge} 3\right)$ & Vol. $20 \mathrm{w} \%\left(\mathrm{~cm}^{\wedge} 3\right)$ & Vol. $30 \mathrm{wt} \%\left(\mathrm{~cm}^{\wedge} 3\right)$ & Vol. $40 \mathrm{~m} \%\left(\mathrm{~cm}^{\wedge} 3\right)$ & Vol. $50 \mathrm{w} \% \%\left(\mathrm{~cm}^{\wedge} 3\right)$ & Vol. $60 \mathrm{wt} \%\left(\mathrm{~cm}^{\wedge} 3\right)$ & Vol. $70 \mathrm{wt} \%\left(\mathrm{~cm}^{\wedge} 3\right)$ \\
\hline 0 & 13.847 & 13.379 & 13.98 & 13.078 & 13.747 & 13.84 & 14.337 \\
\hline 0.04 & 14.075 & 13.216 & 14.174 & 13.132 & 13.962 & 13.784 & 14.505 \\
\hline 0.21 & 14.181 & 13.137 & 14.182 & 13.082 & 13.958 & 13.758 & 14.653 \\
\hline 1 & 13.958 & 13.316 & 14.274 & 13.154 & 13.949 & 13.833 & 14.717 \\
\hline 2 & 14.005 & 13.329 & 14.315 & 13.062 & 14.018 & 13.69 & 14.667 \\
\hline 3 & 14.047 & 13.462 & 14.227 & 13.148 & 14.148 & 13.868 & 14.914 \\
\hline 4 & 14.058 & 13.402 & 14.204 & 13.096 & 14.106 & 13.842 & 14.928 \\
\hline 11 & 14.302 & 13.367 & 14.21 & 13.078 & 14.019 & 13.627 & 15.353 \\
\hline 18 & 14.849 & 13.481 & 14.199 & 13.102 & 14.014 & 13.789 & 16.486 \\
\hline 25 & 15.293 & 13.591 & 14.296 & 13.163 & 14.046 & 13.772 & 17.193 \\
\hline 32 & 16.302 & 13.476 & 13.87 & 13.152 & 14.128 & 13.794 & 17.343 \\
\hline 39 & 17.016 & 13.548 & 14.21 & 13.132 & 14.34 & 13.917 & 17.776 \\
\hline 46 & 17.163 & 13.723 & 14.244 & 13.225 & 14.167 & 13.822 & 18.541 \\
\hline 60 & 17.824 & 13.865 & 14.255 & 13.231 & 14.451 & 13.896 & 18.861 \\
\hline 70 & 18.07 & 13.774 & 14.242 & 13.34 & 14.458 & 13.875 & 19.163 \\
\hline 80 & 18.198 & 13.8 & 14.301 & 13.319 & 14.556 & 13.856 & 19.27 \\
\hline 90 & 18.401 & 13.814 & 14.368 & 13.357 & 14.604 & 13.95 & 19.377 \\
\hline
\end{tabular}


Table A.2: Volume Measurements Using a Caliper for Cation (IRN-77), Sample B, Ion Exchange Resin

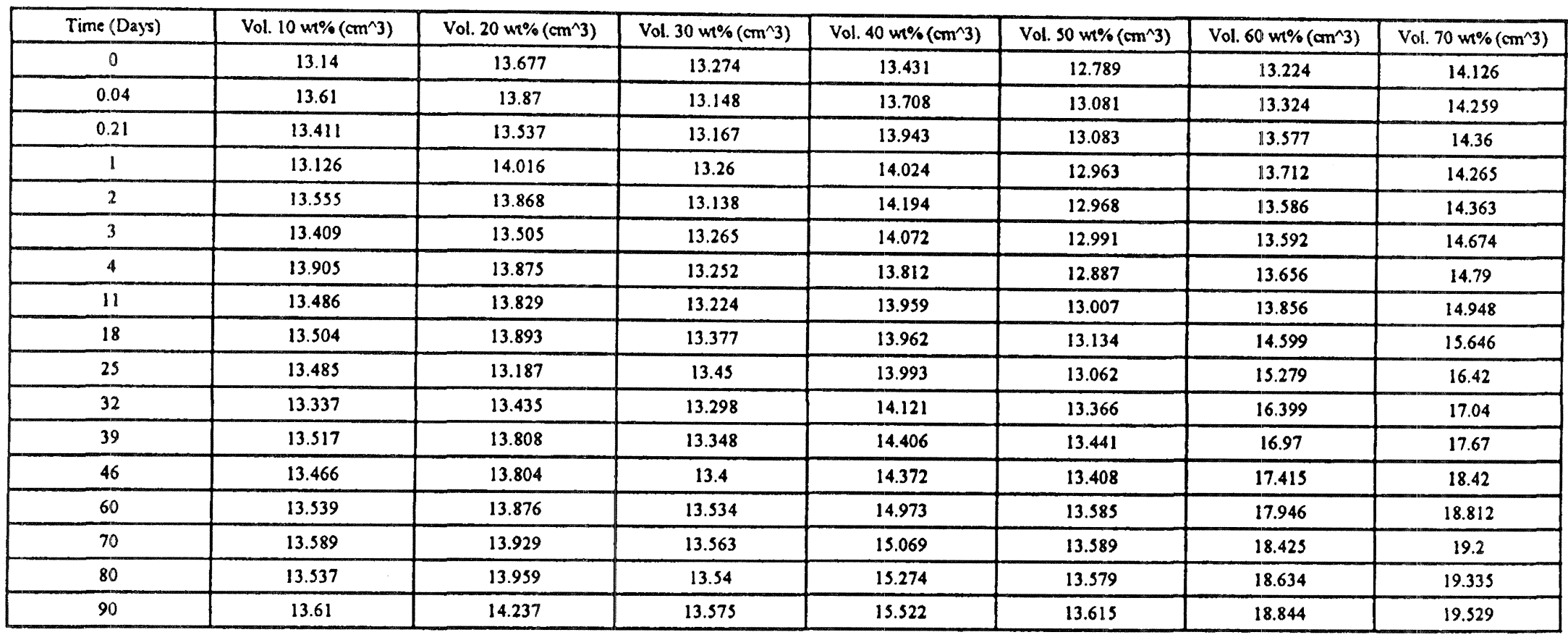


Table A.3: Weight Measurements for Cation (IRN-77), Sample A, Ion Exchange Resin

\begin{tabular}{|c|c|c|c|c|c|c|c|}
\hline Time (Days) & $\begin{array}{c}\text { Wt. 10 wt\% } \\
(\mathrm{gm})\end{array}$ & $\begin{array}{c}\text { Wt. 20 wt\% } \\
(\mathrm{gm})\end{array}$ & $\begin{array}{c}\text { Wt. 30 wt\% } \\
(\mathrm{gm})\end{array}$ & $\begin{array}{c}\text { Wt. 40 wt\% } \\
(\mathrm{gm})\end{array}$ & $\begin{array}{c}\text { Wt. 50 wt\% } \\
(\mathrm{gm})\end{array}$ & $\begin{array}{c}\text { Wt. 60 wt\% } \\
(\mathrm{gm})\end{array}$ & $\begin{array}{c}\text { Wt. 70 wt\% } \\
(\mathrm{gm})\end{array}$ \\
\hline 0 & 12.05 & 12.58 & 12.43 & 14.15 & 12.71 & 14.74 & 15.49 \\
\hline 0.04 & 12.05 & 12.6 & 12.42 & 14.15 & 12.73 & 14.77 & 15.52 \\
\hline 0.21 & 12.06 & 12.56 & 12.43 & 14.17 & 12.77 & 14.8 & 15.58 \\
\hline 1 & 12.11 & 12.61 & 12.48 & 14.17 & 12.71 & 14.81 & 15.61 \\
\hline 2 & 12.08 & 12.58 & 12.48 & 14.19 & 12.71 & 14.8 & 15.63 \\
\hline 3 & 12.1 & 12.55 & 12.47 & 14.19 & 12.77 & 14.88 & 15.73 \\
\hline 4 & 12.03 & 12.58 & 12.43 & 14.21 & 12.74 & 14.92 & 15.78 \\
\hline 11 & 12.05 & 12.59 & 12.44 & 14.24 & 12.74 & 15.18 & 16.23 \\
\hline 18 & 12.05 & 12.6 & 12.46 & 14.26 & 12.74 & 15.69 & 16.98 \\
\hline 25 & 12.07 & 12.6 & 12.47 & 14.28 & 12.75 & 15.8 & 17.58 \\
\hline 32 & 12.07 & 12.58 & 12.47 & 14.31 & 12.76 & 16.72 & 18.24 \\
\hline 39 & 12.07 & 12.6 & 12.48 & 14.34 & 12.77 & 17.4 & 18.83 \\
\hline 46 & 12.08 & 12.6 & 12.47 & 14.36 & 12.76 & 18.02 & 19.43 \\
\hline 60 & 12.08 & 12.6 & 12.48 & 14.39 & 12.78 & 18.68 & 19.74 \\
\hline 70 & 12.09 & 12.62 & 12.5 & 14.44 & 12.79 & 19.07 & 20.06 \\
\hline 80 & 12.09 & 12.62 & 12.51 & 14.47 & 12.79 & 19.25 & 20.24 \\
\hline 90 & 12.09 & 12.62 & 12.51 & 14.5 & 12.79 & 19.38 & 20.35 \\
\hline
\end{tabular}

Table A.4: Weight Measurements for Cation (IRN-77), Sample B, Ion Exchange Resin

\begin{tabular}{|c|c|c|c|c|c|c|c|}
\hline Time (Days) & $\begin{array}{c}\text { Wt. } 10 \mathrm{wt} \% \\
(\mathrm{gm})\end{array}$ & $\begin{array}{c}\text { Wt. 20 wt\% } \\
(\mathrm{gm})\end{array}$ & $\begin{array}{c}\text { Wt. 30 wt\% } \\
(\mathrm{gm})\end{array}$ & $\begin{array}{c}\text { Wt. 40 wt\% } \\
(\mathrm{gm})\end{array}$ & $\begin{array}{c}\text { Wt. 50 wt\% } \\
(\mathrm{gm})\end{array}$ & $\begin{array}{c}\text { Wt. 60 wt\% } \\
(\mathrm{gm})\end{array}$ & $\begin{array}{c}\text { Wt. 70 wt\% } \\
(\mathrm{gm})\end{array}$ \\
\hline 0 & 12.1 & 12.16 & 12.96 & 14.31 & 12.17 & 14.35 & 15.27 \\
\hline 0.04 & 12.09 & 12.13 & 12.94 & 14.32 & 12.18 & 14.39 & 15.29 \\
\hline 0.21 & 12.08 & 12.12 & 12.92 & 14.29 & 12.21 & 14.45 & 15.32 \\
\hline 1 & 12.16 & 12.2 & 12.96 & 14.38 & 12.19 & 14.44 & 15.36 \\
\hline 2 & 12.11 & 12.14 & 12.96 & 14.4 & 12.17 & 14.55 & 15.36 \\
\hline 3 & 12.09 & 12.19 & 13 & 14.35 & 12.17 & 14.51 & 15.42 \\
\hline 4 & 12.11 & 12.16 & 12.98 & 14.39 & 12.18 & 14.55 & 15.45 \\
\hline 11 & 12.09 & 12.17 & 12.99 & 14.45 & 12.19 & 14.87 & 15.72 \\
\hline 18 & 12.11 & 12.18 & 13.01 & 14.51 & 12.2 & 15.45 & 16.27 \\
\hline 25 & 12.12 & 12.18 & 13.02 & 14.56 & 12.21 & 16.13 & 16.83 \\
\hline 32 & 12.14 & 12.17 & 13.03 & 14.63 & 12.21 & 16.74 & 17.54 \\
\hline 39 & 12.12 & 12.19 & 13.04 & 14.69 & 12.22 & 17.38 & 18.21 \\
\hline 46 & 12.14 & 12.19 & 13.06 & 14.77 & 12.23 & 17.98 & 19.07 \\
\hline 60 & 12.13 & 12.2 & 13.06 & 14.87 & 12.24 & 18.66 & 19.56 \\
\hline 70 & 12.14 & 12.19 & 13.08 & 14.99 & 12.24 & 19.13 & 20 \\
\hline 80 & 12.15 & 12.19 & 13.09 & 15.08 & 12.25 & 19.38 & 20.2 \\
\hline 90 & 12.15 & 12.21 & 13.11 & 15.23 & 12.25 & 19.59 & 20.38 \\
\hline
\end{tabular}


Table A.5: Volume Measurements Using a Caliper for Anion (IRN-78), Sample A, Ion Exchange Resin

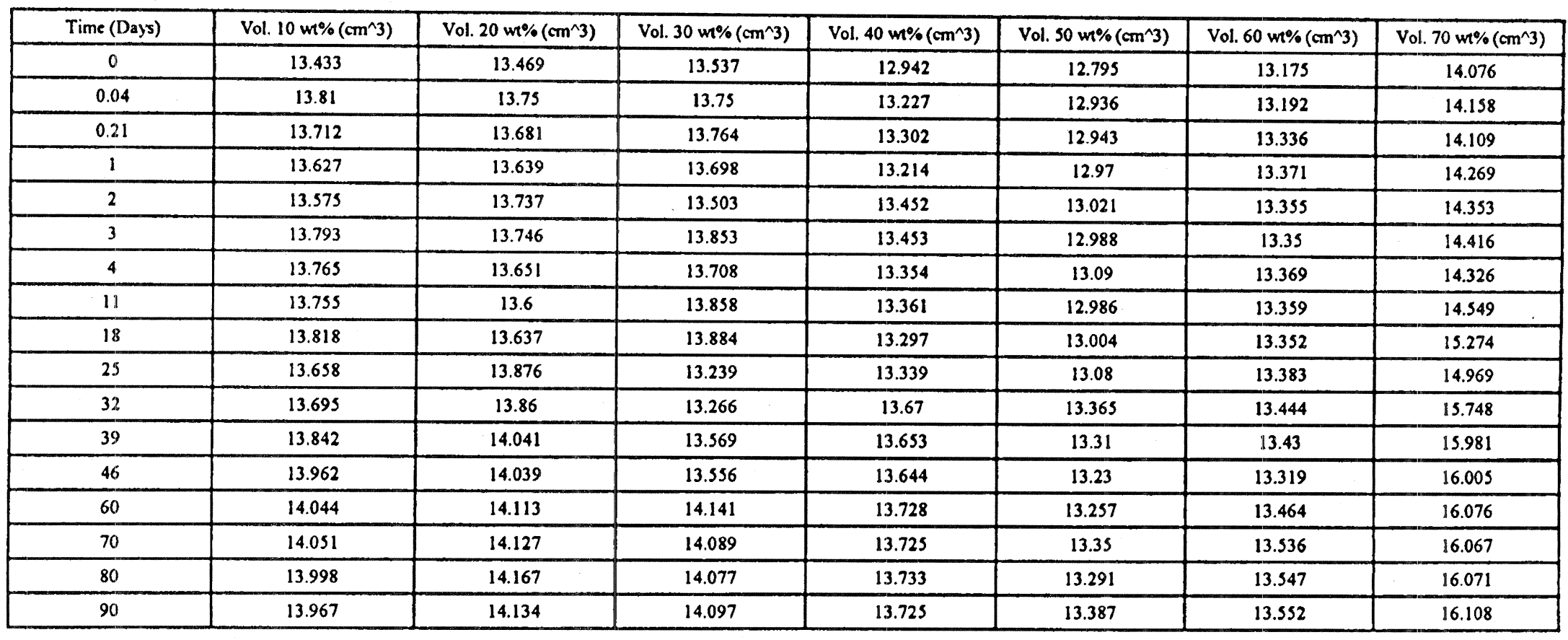


Table A.6: Volume Measurements Using a Caliper for Anion (IRN-78), Sample B, Ion Exchange Resin

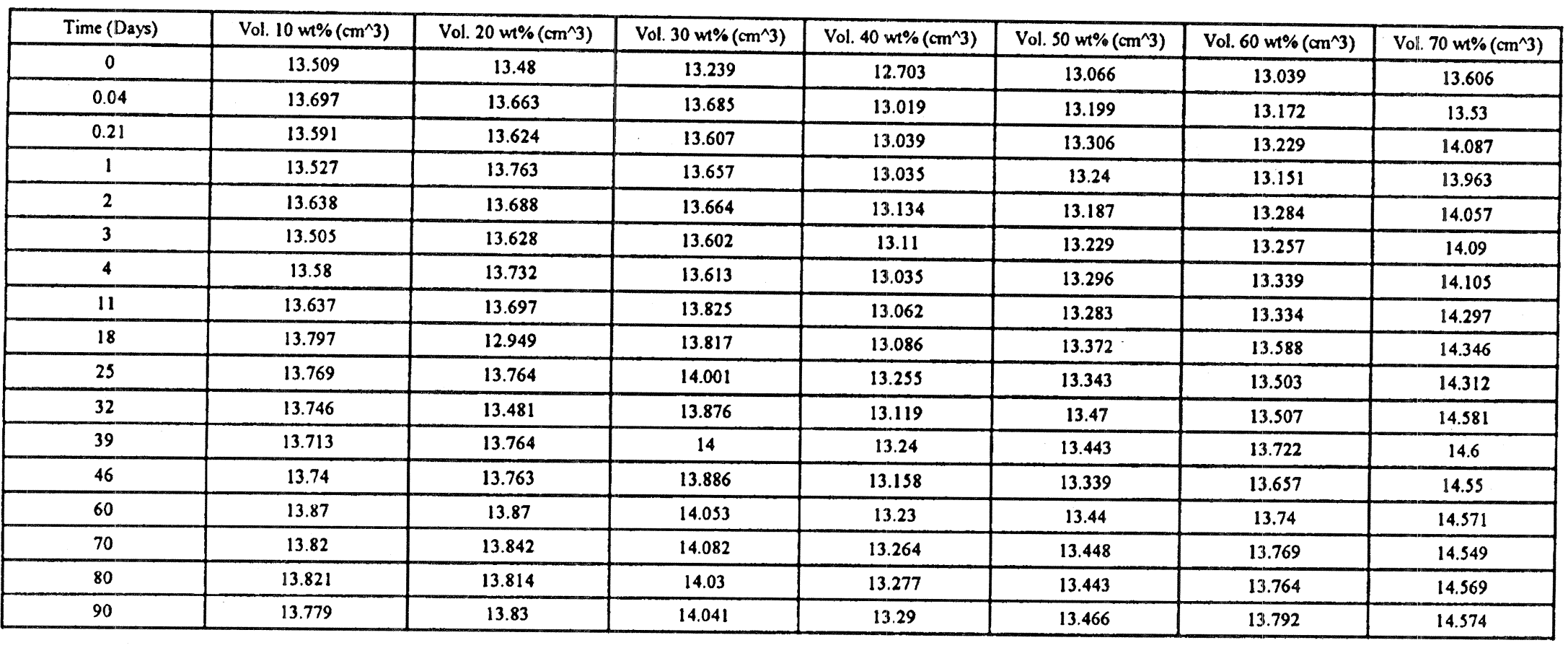


Table A.7: Weight Measurements for Anion (IRN-78), Sample A, Ion Exchange Resin

\begin{tabular}{|c|c|c|c|c|c|c|c|}
\hline Time (Days) & $\begin{array}{c}\text { Wt. } 10 w t \% \\
(\mathrm{gm})\end{array}$ & $\begin{array}{c}\text { Wt. 20wt\% } \\
(\mathrm{gm})\end{array}$ & $\begin{array}{c}\text { Wt. 30 wt\% } \\
(\mathrm{gm})\end{array}$ & $\begin{array}{c}\text { Wt. 40wt\% } \\
(\mathrm{gm})\end{array}$ & $\begin{array}{c}\text { Wt. 50 wt\% } \\
(\mathrm{gm})\end{array}$ & $\begin{array}{c}\text { Wt. 60 wt\% } \\
(\mathrm{gm})\end{array}$ & $\begin{array}{c}\text { Wt. 70 wt\% } \\
(\mathrm{gm})\end{array}$ \\
\hline 0 & 12.26 & 12.59 & 12.26 & 12.23 & 12.3 & 12.61 & 12.9 \\
\hline 0.04 & 12.26 & 12.58 & 12.23 & 12.24 & 12.3 & 12.63 & 12.95 \\
\hline 0.21 & 12.26 & 12.58 & 12.26 & 12.25 & 12.35 & 12.65 & 12.98 \\
\hline 1 & 12.27 & 12.64 & 12.28 & 12.26 & 12.3 & 12.63 & 13.03 \\
\hline 2 & 12.3 & 12.58 & 12.25 & 12.25 & 12.31 & 12.65 & 13 \\
\hline 3 & 12.21 & 12.59 & 12.28 & 12.3 & 12.35 & 12.63 & 13.03 \\
\hline 4 & 12.28 & 12.58 & 12.27 & 12.27 & 12.32 & 12.64 & 13.06 \\
\hline 11 & 12.26 & 12.59 & 12.27 & 12.3 & 12.34 & 12.67 & 13.3 \\
\hline 18 & 12.27 & 12.59 & 12.27 & 12.33 & 12.35 & 12.68 & 13.67 \\
\hline 25 & 12.28 & 12.6 & 12.28 & 12.35 & 12.35 & 12.66 & 13.99 \\
\hline 32 & 12.28 & 12.6 & 12.28 & 12.32 & 12.35 & 12.69 & 14.18 \\
\hline 39 & 12.28 & 12.62 & 12.28 & 12.34 & 12.37 & 12.72 & 14.29 \\
\hline 46 & 12.29 & 12.62 & 12.29 & 12.37 & 12.39 & 12.73 & 14.46 \\
\hline 60 & 12.27 & 12.62 & 12.28 & 12.41 & 12.38 & 12.74 & 14.56 \\
\hline 70 & 12.29 & 12.61 & 12.29 & 12.39 & 12.38 & 12.74 & 14.56 \\
\hline 80 & 12.29 & 12.61 & 12.3 & 12.34 & 12.4 & 12.76 & 14.59 \\
\hline 90 & 12.29 & 12.62 & 12.29 & 12.35 & 12.4 & 12.77 & 14.58 \\
\hline
\end{tabular}

Table A.8: Weight Measurements for Anion (IRN-78), Sample B, Ion Exchange Resin

\begin{tabular}{|c|c|c|c|c|c|c|c|}
\hline Time (Days) & $\begin{array}{c}\text { Wt. 10 wt\% } \\
(\mathrm{gm})\end{array}$ & $\begin{array}{c}\text { Wt. 20 wt\% } \\
(\mathrm{gm})\end{array}$ & $\begin{array}{c}\text { Wt. 30 wt\% } \\
(\mathrm{gm})\end{array}$ & $\begin{array}{c}\text { Wt. 40 wt\% } \\
(\mathrm{gm})\end{array}$ & $\begin{array}{c}\text { Wt. 50 wt\% } \\
(\mathrm{gm})\end{array}$ & $\begin{array}{c}\text { Wt. 60 wt\% } \\
(\mathrm{gm})\end{array}$ & $\begin{array}{c}\text { Wt. 70 wt\% } \\
(\mathrm{gm})\end{array}$ \\
\hline 0 & 12.23 & 12.19 & 12.59 & 12.06 & 12.24 & 12.53 & 12.82 \\
\hline 0.04 & 12.21 & 12.17 & 12.56 & 12.02 & 12.23 & 12.54 & 12.83 \\
\hline 0.21 & 12.25 & 12.18 & 12.53 & 12.04 & 12.28 & 12.54 & 12.85 \\
\hline 1 & 12.28 & 12.22 & 12.61 & 12.05 & 12.23 & 12.55 & 12.85 \\
\hline 2 & 12.24 & 12.2 & 12.55 & 12.07 & 12.25 & 12.57 & 12.83 \\
\hline 3 & 12.24 & 12.18 & 12.61 & 12.1 & 12.27 & 12.57 & 12.83 \\
\hline 4 & 12.25 & 12.2 & 12.59 & 12.05 & 12.26 & 12.53 & 12.86 \\
\hline 11 & 12.24 & 12.21 & 12.6 & 12.06 & 12.29 & 12.57 & 12.9 \\
\hline 18 & 12.25 & 12.22 & 12.61 & 12.06 & 12.31 & 12.61 & 12.92 \\
\hline 25 & 12.25 & 12.24 & 12.61 & 12.11 & 12.3 & 12.59 & 12.94 \\
\hline 32 & 12.25 & 12.19 & 12.62 & 12.09 & 12.29 & 12.6 & 12.95 \\
\hline 39 & 12.25 & 12.22 & 12.62 & 12.08 & 12.32 & 12.63 & 12.98 \\
\hline 46 & 12.26 & 12.23 & 12.62 & 12.08 & 12.33 & 12.63 & 13.03 \\
\hline 60 & 12.26 & 12.24 & 12.62 & 12.09 & 12.34 & 12.65 & 13.03 \\
\hline 70 & 12.25 & 12.24 & 12.63 & 12.1 & 12.35 & 12.66 & 13.04 \\
\hline 80 & 12.26 & 12.24 & 12.63 & 12.09 & 12.37 & 12.66 & 13.07 \\
\hline 90 & 12.27 & 12.24 & 12.62 & 12.09 & 12.38 & 12.68 & 13.07 \\
\hline
\end{tabular}


Table A.9: Volume Measurements Using a Caliper for Mixed Bed (2:1 ratio), Sample A, Ion Exchange Resin

\begin{tabular}{|c|c|c|c|c|c|c|c|}
\hline Time (Days) & Vol. $10 \mathrm{~m} \%\left(\mathrm{~cm}^{\wedge} 3\right)$ & Vol. $20 \mathrm{w} \%\left(\mathrm{~cm}^{\wedge} 3\right)$ & Vol. $30 \mathrm{~m} \%\left(\mathrm{~cm}^{\wedge} 3\right)$ & Vol. $40 \mathrm{~m} \%\left(\mathrm{~cm}^{\wedge} 3\right)$ & Vol. $50 \mathrm{~m} \%\left(\mathrm{~cm}^{\wedge} 3\right)$ & Vol. $60 \mathrm{wt} \%\left(\mathrm{~cm}^{\wedge} 3\right)$ & Vol. $70 \mathrm{wt} \%\left(\mathrm{~cm}^{\wedge} 3\right)$ \\
\hline 0 & 12.922 & 12.272 & 12.378 & 12.98 & 12.683 & 12.951 & 13.138 \\
\hline 0.04 & 13.035 & 12.411 & 12.649 & 13.028 & 12.901 & 12.979 & 13.443 \\
\hline 0.21 & 12.99 & 12.585 & 12.732 & 13.091 & 12.762 & 13.089 & 13.323 \\
\hline 1 & 13.002 & 12.455 & 12.62 & 13.044 & 12.865 & 12.947 & 13.402 \\
\hline 2 & 13.03 & 12.336 & 12.605 & 13.212 & 12.924 & 13.139 & 13.361 \\
\hline 3 & 13.027 & 12.604 & 12.682 & 13.134 & 12.952 & 13.1 & 13.341 \\
\hline 4 & 12.86 & 12.628 & 12.677 & 13.087 & 12.977 & 13.132 & 13.31 \\
\hline III & 12.825 & 12.602 & 12.722 & 13.072 & 12.818 & 13.206 & 13.406 \\
\hline 18 & 12.901 & 12.722 & 12.781 & 13.067 & 12.975 & 13.34 & 13.58 \\
\hline 25 & 12.919 & 12.742 & 12.759 & 13.047 & 12.941 & 13.368 & 13.606 \\
\hline 32 & 13.101 & 12.555 & 12.805 & 13.109 & 13.285 & 13.392 & 13.855 \\
\hline 39 & 13.254 & 12.779 & 12.778 & 13.122 & 13.211 & 13.484 & 14.051 \\
\hline 46 & 13.288 & 12.757 & 12.855 & 12.936 & 13.295 & 13.559 & 14.257 \\
\hline 60 & 13.446 & 12.75 & 12.874 & 12.999 & 13.292 & 13.744 & 14.317 \\
\hline 70 & 13.355 & 12.797 & 12.966 & 13.05 & 13.399 & 13.778 & 14.52 \\
\hline 80 & 13.349 & 12.833 & 12.978 & 13.035 & 13.42 & 13.797 & 14.572 \\
\hline 90 & 13.26 & 12.928 & 12.967 & 13.101 & 13.406 & 13.918 & 14.758 \\
\hline
\end{tabular}


Table A.10: Volume Measurements Using a Caliper for Mixed Bed(2:1 ratio), Sample B, Ion Exchange Resin

\begin{tabular}{|c|c|c|c|c|c|c|c|}
\hline Time (Days) & Vol. $10 \mathrm{mt} \%\left(\mathrm{~cm}^{\wedge} 3\right)$ & Vol. $20 \mathrm{~m} \%\left(\mathrm{~cm}^{\wedge} 3\right)$ & Vol. $30 \mathrm{w} \%\left(\mathrm{~cm}^{\wedge} 3\right)$ & Vol. $40 \mathrm{w} \%\left(\mathrm{~cm}^{\wedge} 3\right)$ & Vol. $50 \mathrm{wt} \%\left(\mathrm{~cm}^{\wedge} 3\right)$ & Vol. $60 \mathrm{~m} \%\left(\mathrm{~cm}^{\wedge} 3\right)$ & Vol. $70 \mathrm{wt} \%\left(\mathrm{~cm}^{\wedge} 3\right)$ \\
\hline 0 & 12.49 & 13.062 & 12.616 & 12.82 & 13.147 & 12.813 & 13.014 \\
\hline 0.04 & 12.892 & 13.305 & 12.911 & 12.835 & 13.29 & 12.966 & 12.889 \\
\hline 0.21 & 12.806 & 13.148 & 12.745 & 12.833 & 13.35 & 13.101 & 12.931 \\
\hline 1 & 12.688 & 13.002 & 13.009 & 12.805 & 13.337 & 13.096 & 12.88 \\
\hline 2 & 12.814 & 13.355 & 12.801 & 12.938 & 13.403 & 13.106 & 12.939 \\
\hline 3 & 12.794 & 13.092 & 12.869 & 12.955 & 13.257 & 13.095 & 12.926 \\
\hline 4 & 12.897 & 13.193 & 12.928 & 12.882 & 13.188 & 13.136 & 12.855 \\
\hline 11 & 12.763 & 13.131 & 13.049 & 12.788 & 13.207 & 13.054 & 13.168 \\
\hline 18 & 12.808 & 13.166 & 13.057 & 12.854 & 13.378 & 13.204 & 13.297 \\
\hline 25 & 12.783 & 13.225 & 13.032 & 12.754 & 13.321 & 13.206 & 13.635 \\
\hline 32 & 12.851 & 13.1 & 13.068 & 12.999 & 13.507 & 13.406 & 13.704 \\
\hline 39 & 12.829 & 13.366 & 13.13 & 12.986 & 13.436 & 13.451 & 14.219 \\
\hline 46 & 12.953 & 13.384 & 13.048 & 13.115 & 13.383 & 13.451 & 14.524 \\
\hline 60 & 12.974 & 13.363 & 13.108 & 13.245 & 13.54 & 13.61 & 14.551 \\
\hline 70 & 12.989 & 13.362 & 13.157 & 13.228 & 13.537 & 13.617 & 14.81 \\
\hline 80 & 13.013 & 13.282 & 13.143 & 13.295 & 13.508 & 13.666 & 14.993 \\
\hline 90 & 12.952 & 13.37 & 13.166 & 13.302 & 13.555 & 13.735 & 15.304 \\
\hline
\end{tabular}

